\title{
Health Perceptions of Cancer Survivors Harvesting at an Urban Garden
}

\section{THESIS}

Presented in Partial Fulfillment of the Requirements for the Degree Master of Science in the Graduate School of The Ohio State University

\author{
By \\ Alexis Joseph, B.S. \\ Graduate Program in Allied Medical Professions \\ The Ohio State University \\ 2014 \\ Thesis Committee: \\ Dr. Colleen Spees, Advisor \\ Dr. Kay Wolf \\ Dr. Amy Darragh \\ Felisha Lyons
}


Copyright by

Alexis Joseph

2014 


\begin{abstract}
Due to significant advances in prevention, early detection, and treatment of cancer, the number of cancer survivors increases dramatically each year. However, as a result of the effects of cancer treatment, genetic predisposition, and lifestyle behaviors, cancer survivors are at much greater risk for multiple comorbidities. Indeed, in healthy populations, access to fresh produce in an urban garden-based setting has been effective in improving dietary intakes, physical activity levels, and social support. Despite these findings, no harvesting interventions specific to cancer survivors have been published. Three focus groups consisting of 28 adult cancer survivors were conducted to determine if an urban harvesting initiative improved perceptions of health and wellness in cancer survivors. Participants' responses resulted in four major overarching themes: (1) perceptions of improved mental and physical health, (2) adherence to a plant-based diet and healthy modifications in cooking and meal planning, (3) greater sense of community and social support, and (4) challenges to harvesting. These findings provide preliminary results supporting positive outcomes associated with harvesting at an urban garden setting for cancer survivors. These results will inform future interventions aimed at improving overall adherence to evidence-based guidelines for cancer survivorship.
\end{abstract}

Keywords: Nutrition, Gardening, Cancer Survivor, Qualitative Research, Focus Groups 


\section{Dedication}

This thesis is dedicated to my grandpa Albert Joseph, whose passion for gardening, writing, photography, and all things beautiful lives on in me each day and to my grandpa Allen Katz, who knew to never pass up a roadside farm market. 


\section{Acknowledgments}

I would first like to sincerely thank my advisor, professor and mentor, Dr. Spees,

for her constant support, enthusiasm, patience, and willingness to go above and beyond to make this thesis the absolute best it could be. Your sincere and approachable demeanor toward students is exceptional; and your dedication to nutrition and cancer research never ceases to amaze me. I feel extremely blessed to have done research with such a rewarding population under the guidance of such a great advisor. I truly could not have done it without you.

I would also like to thank my graduate committee members, Dr. Kay Wolf, Dr. Amy Darragh, and Felisha Lyons for their extremely helpful feedback, expertise and guidance during not only the thesis process, but also throughout my graduate career. Last but not least, I would like to thank my wonderful parents, Paul and Eileen Joseph, whose endless support and love have molded me into the passionate person I am today. Thank you for encouraging me to write when I can't find the words, cook when I don't have a recipe, and live life to the fullest each day. 
Vita

$2008 \ldots \ldots \ldots \ldots . .$. Solon High School
Program in Medical Dietetics, The Ohio
State University

Fields of Study

Major Field: Allied Medical Professions 


\section{Table of Contents}

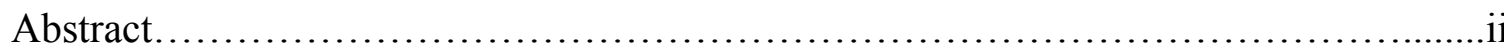

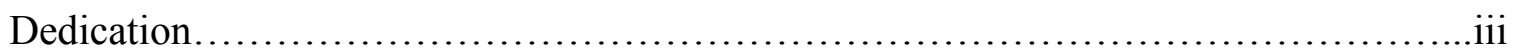

Acknowledgments.........................................................

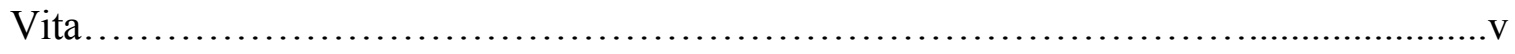

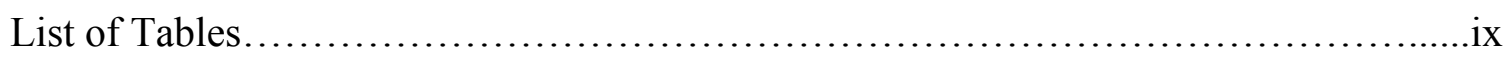

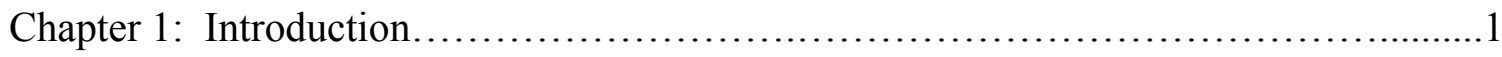

Background of the Problem...............................................

Statement of the Problem.........................................................

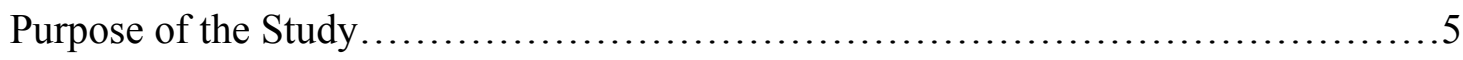

Objectives of the Study................................................. 5

Chapter 2: Literature Review.............................................. 7

Health of Cancer Survivors in America.........................................

The AICR's Recommendations for Cancer Prevention.............................8

Need for Targeted Nutrition Interventions................................... 12

Garden-Based Interventions............................................. 14

Focus Groups........................................................ 16

Chapter 3: Methods......................................................20

Research Design...................................................... 21

Focus Group Questions...................................................21 
Instrument Development............................................... 22

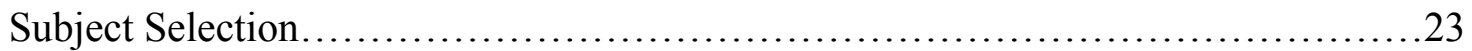

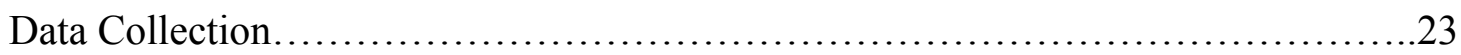

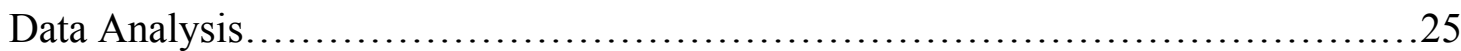

Chapter 4: Results and Discussion..........................................27

Results................................................................27

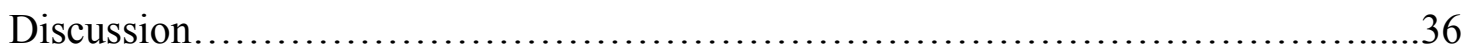

Improved Health...................................................... 36

Improved Nutrition................................................... 39

Support.........................................................44

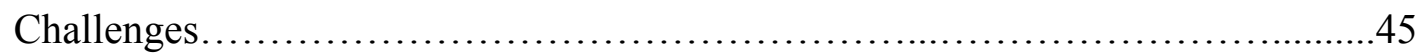

Limitations........................................................48

Implications for Practice and Future Research.................................49

Chapter 5: Health Perceptions of Cancer Survivors Harvesting at an Urban Garden......52

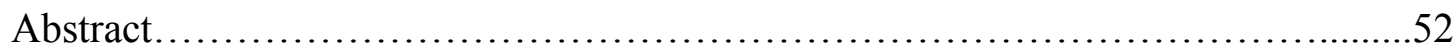

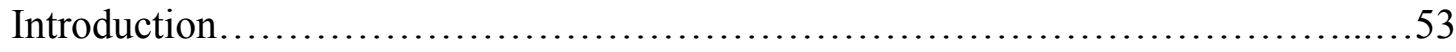

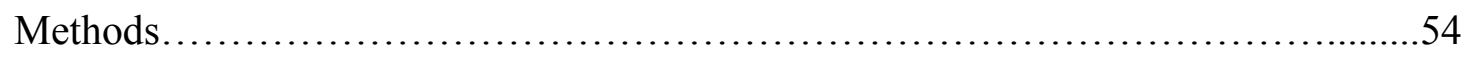

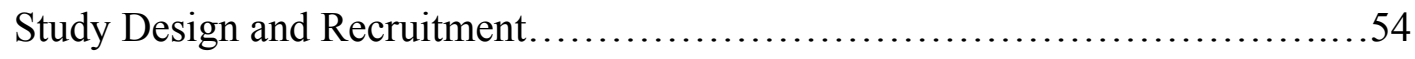

Analysis...............................................................56

Results................................................................57

Improved Health...................................................... 58

Improved Nutrition................................................59 


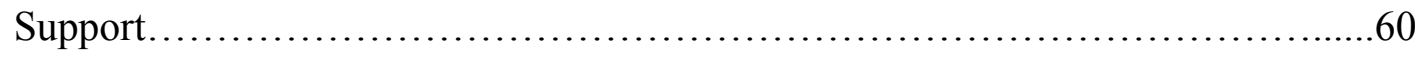

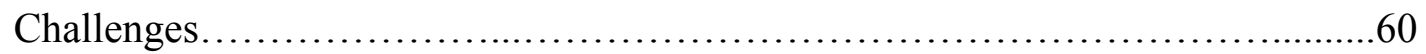

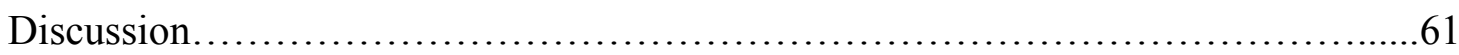

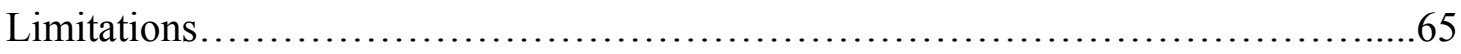

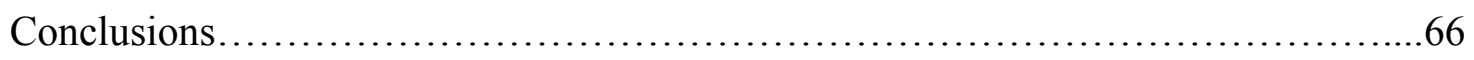

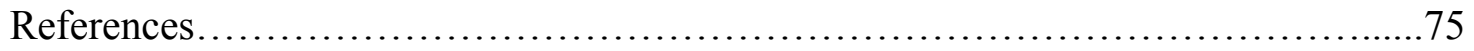

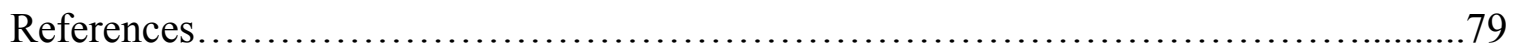

Appendix A: Letter to Participant............................................... 86

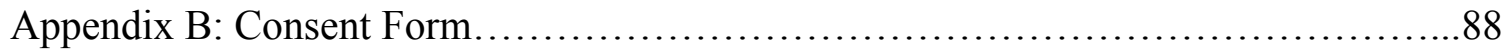

Appendix C: Subject Characteristics Survey........................................92

Appendix D: Food Security Questionnaire.........................................95 


\section{List of Tables}

Table 4.1 Subject Characteristics of Cancer Survivors Harvesting at an Urban

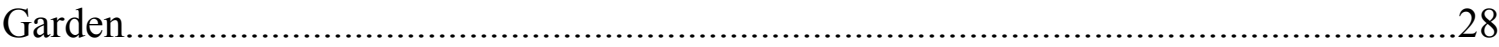

Table 4.2 Food Security Status of Cancer Survivors Harvesting at an Urban

Garden

Table 4.3 Overarching Themes from Participant Focus Groups Determining the Health

Perceptions of Cancer Survivors Harvesting at an Urban Garden..................................30

Table 5.1 Subject Characteristics of Cancer Survivors Harvesting at an Urban

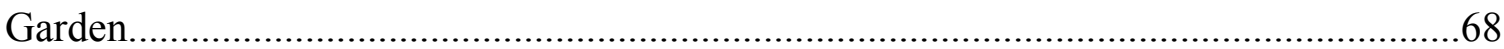

Table 5.2 Representativeness of Garden of Hope Participants.....................................69

Table 5.3 Food Security Status of Cancer Survivors Harvesting at an Urban

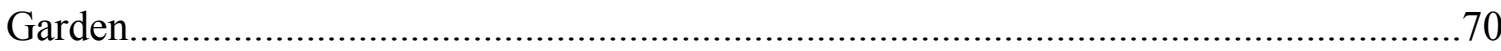

Table 5.4 Focus Group Open-Ended Discussion Question Thread ....................71

Table 5.5 Overarching Themes from Participant Focus Groups.......................72

Figure 5.1 Recruitment and Flow of Participants Through Study .................... 74 


\section{Chapter 1: Introduction}

\section{Background of the Problem}

A cancer survivor is defined by the American Cancer Society (ACS) as an individual who has been diagnosed with cancer, from the time of diagnosis through the duration of life. ${ }^{1}$ The three phases of cancer survival include: (1) the time from diagnosis to the end of the first treatment; (2) the transition from finishing treatment to survival; and (3) long term survival. ${ }^{1}$ According to the ACS's most recent Cancer Treatment and Survivorship Facts and Figures, as of January 1, 2012, an estimated 13.7 million Americans were living with a history of cancer. As a result of advances in prevention, early detection, and treatment of cancer, there has been a steady decline in the cancer death rate over the last two decades. ${ }^{2}$ An estimated $64 \%$ of those diagnosed with cancer are expected to be alive in five years, compared to less than $50 \%$ in $1971 .^{3}$ It is also estimated that by 2050 , the total number of recorded cancer survivors in the world may approach 70 million. $^{4}$

The most common cancer among male survivors is prostate cancer (43\%), while breast is the most common cancer among female survivors $(41 \%) .{ }^{1}$ Research indicates that the majority of survivors $(64 \%)$ were diagnosed 5 or more years ago, while only $15 \%$ of survivors were diagnosed 20 or more years ago. ${ }^{1}$ Nearly half of all cancer survivors are at least 70 years of age and only $5 \%$ of survivors are younger than 40 years of age. ${ }^{1}$ 
Due to advances in early detection and treatment, the number of cancer survivors increases dramatically each year. However, the effects of cancer treatment, genetic predisposition, and lifestyle behaviors put cancer survivors at much greater risk for comorbid conditions including recurring primary cancers, secondary malignancies, cardiovascular disease (CVD), osteoporosis, diabetes, and functional decline. ${ }^{5}$ After treatment, survivors are at an increased risk for a variety of ongoing, long-term symptoms including chronic pain and fatigue, cognitive problems, damage to the heart, decreased bone density, and decreased lung function. ${ }^{1}$ Modifiable lifestyle behaviors such as engaging in regular physical activity, consuming a primarily plant-based diet, and maintaining a healthy body weight may not only improve cancer outcomes for survivors, but overall functioning and quality of life as well. ${ }^{4-6}$ According to the National Cancer Institute (NCI), an estimated 35\% of cancer deaths could be prevented by modifiable lifestyle behaviors. ${ }^{1,7}$ The American Institute for Cancer Research's (AICR) evidencebased guidelines for cancer prevention and survivorship recommend adopting a plantbased diet, engaging in regular physical activity and maintaining a lean body weight in addition to other key recommendations. ${ }^{4}$ The ACS also promotes healthy behaviors such as physical activity, weight management via healthy diet, and smoking cessation to mitigate symptoms and improve overall health and functioning throughout survivorship. ${ }^{1}$

\section{Statement of the Problem}

Each year the number of cancer survivors increases significantly. ${ }^{1}$ Though survivors are living longer, they are at greater risk for long-term health complications resulting from cancer treatment, genetic factors, and lifestyle choices. ${ }^{5}$ Specifically, the 
AICR's guidelines for cancer prevention and survivorship recommend adopting a plantbased diet, engaging in regular exercise, and maintaining a lean body weight. ${ }^{4}$ More than one-third of all cancers could be prevented by adhering to these guidelines. ${ }^{7}$ There is conflicting evidence regarding the health behaviors of cancer survivors. ${ }^{8} 9$ While some studies show that survivors are often inactive, overweight or obese, and consume a diet high in saturated fat and low in fruits and vegetables, ${ }^{10,11}$ others show that survivors are healthier than the general population. ${ }^{8}$ Research indicates that lifestyle interventions encouraging diet and physical activity modifications may slow down the progression of these complications. ${ }^{4,6}$

Urban harvesting is one approach to encourage adherence to cancer lifestyle behavior guidelines. Providing access to fresh produce through gardening interventions has been shown to improve mental health, socialization, physical functioning, and perception of health-related well-being. ${ }^{12-14}$ Despite a growing body of evidence promoting gardening interventions in both youth and adults, very few studies focus on high-risk populations. ${ }^{3,12,14-17,18,19-23}$ Blair et al. investigated the impact of gardening on cancer survivors. ${ }^{24}$ In this study, pairing cancer survivors with master gardeners led to improvements in survivor physical functioning, produce consumption, and physical activity levels. ${ }^{24}$ Given the range of health benefits of gardening and the proven feasibility, novel cancer survivor gardening interventions show great potential for sustainability and widespread dissemination.

JamesCare for Life (JCFL), an extension of Ohio State University's Comprehensive Cancer Center (OSU-CCC), provides a variety of resources and services 
to assist cancer patients and their families with navigating their cancer journey. Among the JCFL offerings, nutrition programs educate survivors about the critical role of food and nutrition for cancer prevention and survivorship. One such program is the Garden of Hope $(\mathrm{GOH})$, a community garden located at The Ohio State University's Waterman Farm available free of charge to cancer survivors and their primary caregivers. Featuring an herb garden and a wide variety of produce, the $\mathrm{GOH}$ provides access to harvests three times per week in two hour shifts during the growing season. Participants and caregivers attend an orientation aimed at providing harvesting instructions, safe food handling practices, and gardening tips. Each participant and his or her caregiver also receives a special harvest bag. During the scheduled harvest times, dietetics students as well as JamesCare volunteers and staff are available to lend assistance and help answer questions. There were 170 unique GOH participants during the 2013 growing season. Of the 585 total check-ins, each participant averaged 3.4 check-ins for the season. Each harvest session averaged 15.4 participants.

JCFL conducted a survivor survey in 2013 of current JamesCare participants in order to collect basic demographics and active participant preferences to improve overall JCFL programming. ${ }^{25}$ The survey was offered at the conclusion of JamesCare classes in place of the usual program-specific evaluations and was also emailed to those who had expressed interest in JCFL's GOH during Cancer Survivors Day 2012. Eighty-seven out of the 347 active JCFL participants $(25.1 \%)$ completed the survey. The survey indicated that the most common primary cancers were breast (54.8\%) and prostate $(6.8 \%)$. The majority of respondents were female (81\%) and between the ages of 50-79. Nearly half 
(46\%) worked part time or full time. Ninety percent of the respondents self-reported race as Caucasian or white, $8 \%$ African-American, $1 \%$ Asian or Pacific Islander, and 1\% "other."

To our knowledge, there are no studies that examine the impact of urban harvesting on cancer survivors' diet, activity levels, and health perceptions. The GOH provides a novel setting for analyzing the relationship between urban harvesting and adherence to the AICR's cancer survivorship guidelines. A deeper understanding of the wide range of effects that harvesting has on cancer survivors could have a significant impact on improving health outcomes in this vulnerable population.

\section{Purpose of the Study}

The purpose of this study was to determine the perceptions of cancer survivors participating in an urban harvesting initiative. The perceptions and impact of receiving and utilizing the produce harvested during one growing season at the $\mathrm{GOH}$ was evaluated to inform future interventions aimed at improving overall adherence to the AICR's evidence-based guidelines for cancer prevention and survivorship. The results of this study provide insights into many reported positive health outcomes and some barriers of harvesting produce in an urban garden setting for cancer survivors.

\section{Objectives of the Study}

This study will address the following objectives:

1. To identify positive outcomes, barriers and challenges of urban harvesting for cancer survivors.

2. To determine the impact harvesting at the Garden of Hope has on survivors' health 
perceptions.

3. To determine how produce harvested at the Garden of Hope is being used by the cancer survivors. 


\section{Chapter 2: Literature Review}

\section{Health of Cancer Survivors in America}

There is conflicting evidence as to whether or not the health behaviors of cancer survivors mirror those of the general population. ${ }^{8,9}$ While some studies show that survivors are often inactive, overweight or obese, and consume a diet high in saturated fat and low in fruits and vegetables, ${ }^{10,11}$ others show that survivors are healthier than the general population. ${ }^{8}$ A population-based study was conducted by Belizzi et al. in 2005 using National Health Interview Survey (NHIS) data to evaluate the health behaviors of cancer survivors, including smoking, alcohol use and physical activity (PA). They found that the survivors and the noncancer controls were similar regarding smoking status and alcohol consumption. Though nearly three-fourths of survivors are not meeting the recommendations for physical activity, the study found that survivors are $9 \%$ more likely to meet those recommendations compared with respondents with no history of cancer. ${ }^{8}$ Furthermore, compared with other sites, the study documented that a larger proportion of breast $(28.7 \%)$, prostate $(30.1 \%)$, and gynecologic $(29.4 \%)$ cancer survivors are meeting current physical activity recommendations. ${ }^{8}$ Of note, the study found significant differences in behaviors depending on cancer site. For example, rates of smoking in prostate, breast and colorectal cancer survivors were $23.6 \%$ lower than those of the control group. There were also notable differences in alcohol consumption by cancer site. 
Prostate, lung, larynx, and pharynx cancer survivors showed a higher proportion of moderate-heavy alcohol consumption (more than one drink per day for women and more than two for men). ${ }^{8}$ These findings may in part be attributed to differences in age distributions by cancer site, specifically that some older survivors consume alcohol for its known cardiovascular benefits. ${ }^{8}$

In a 2008 national cross sectional survey, Blanchard et al. examined the prevalence and clustering of physical activity, fruit and vegetable intake (5-A-Day), and smoking across six cancer survivor groups to evaluate health related quality of life (QOL). The study documented that few of the cancer survivors met PA (29.6\% to $47.3 \%)$ and 5-A-Day (14.8\% to $18.2 \%$ ) recommendations. ${ }^{9}$ A similar study reported that $25 \%$ to $42 \%$ of survivors consume adequate amounts of fruits and vegetables. ${ }^{10}$ With regard to smoking, the majority of survivors were meeting the recommendation to avoid tobacco ( $88.1 \%$ to $91.6 \%$ ), which is a higher percentage than the $79.5 \%$ of nonsmoking healthy adults nationally. ${ }^{9}$ Of note, only $5 \%$ of cancer survivors were meeting all three recommendations for PA, 5-A-Day, and smoking.

A 2003 population-based study by Blanchard et al. evaluated physical activity and found that breast cancer survivors were $42 \%$ more likely than healthy controls to engage in vigorous physical activity. Moreover, the study showed that $13 \%$ of breast cancer survivors continued to smoke after diagnosis, which was less than the smoking rate of noncancer controls. ${ }^{15}$

\section{The AICR's Recommendations for Cancer Prevention}

Food, Nutrition and the Prevention of Cancer: a Global Perspective, published in 
2007 by the AICR/World Cancer Research Fund (WCRF) is the most definitive review on food, diet and cancer prevention to date. The report features recommendations based on systematic reviews of the world's research by an international expert panel of renowned scientists. The goal was to examine all of the relevant cancer research in order to create personal and public health recommendations for diet and physical activity aimed at reducing the incidence of cancer. ${ }^{4}$ The report not only provides a body of evidence for policy makers and health professionals, but it also serves as a comprehensive guide to future research, cancer prevention interventions, and global health policy.

According to the AICR/WCRF report, emerging evidence suggests that some aspects of food, nutrition, and/or physical activity specifically improve the condition of cancer survivors. However, there remains a lack of scientific evidence to support modifiable lifestyle behavior recommendations for cancer survivors. The available evidence remains limited due to variability in study design and interpretation, and hasn't yet yielded impressive results. ${ }^{4}$ It is therefore recommended that cancer survivors follow the general recommendations for cancer prevention, including weight management and maintenance, consuming a primarily plant-based diet, and engaging in regular physical activity. AICR and the National Cancer Institute (NCI) estimate that approximately onethird of the 1.5 million cancers that occur in the United States annually could be prevented by changing lifestyle behaviors and adhering to these guidelines. ${ }^{4,7}$ Though the number of randomized clinical trials assessing lifestyle interventions in cancer survivors is increasing, evidence remains quite limited. The small body of existing evidence 
suggests that healthy lifestyle behaviors impact health-related outcomes after the diagnosis of cancer and may increase longevity. ${ }^{5-6,26-27}$

A study by Vergnaud et al. assessed the relationship between adherence to AICR's recommendations for cancer prevention and risk of death. ${ }^{27}$ The study consisted of 378,864 participants from nine European countries between the ages of 29-70 enrolled in the European Prospective Investigation into Cancer and Nutrition study (EPIC). Researchers created a WCRF/AICR score of 0 to 6 for men and 0 to 7 for women (including breast feeding recommendations) based on the current guidelines, with higher scores indicating greater compliance with the recommendations. After 13 years of follow-up, participants with the highest scores had $47 \%$ lower mortality rates than those of participants with the lowest scores. ${ }^{27}$ Furthermore, each single-unit increase in score was associated with a $13 \%$ decrease in mortality rate, corresponding to an additional 1.2 years of life. Though death from respiratory disease was most strongly associated with adherence to the guidelines ( $21 \%$ lower hazard of death per unit increase in score), death from circulatory disease and cancer were also inversely related to the score.

Recommendations on adhering to a plant-based diet and maintaining lean body weight had the strongest influence on the hazards ratio. In sum, this seminal study suggests a significant relationship between compliance to AICR's recommendations for cancer prevention and decreased mortality. These novel findings reinforce the evidence suggesting concurrence with AICR's cancer prevention and survivorship guidelines in order to reduce mortality from chronic disease.

A 2013 study by Hastert investigated the association between meeting six of 
AICR's ten cancer prevention guidelines and breast cancer risk over 6.7 years of followup. ${ }^{28}$ The guidelines were related to body fatness, physical activity, energy-density of foods, plant foods, red and processed meats, and alcohol. The study population consisted of approximately 31,000 postmenopausal women from the Vitamins and Lifestyle study. ${ }^{29}$ At enrollment, the women were between the ages of 50-76 and had no history of breast cancer. At study completion, 899 women had been diagnosed with breast cancer. ${ }^{28}$ The study found that those who followed at least five of AICR's recommendations reduced their risk of developing breast cancer by $60 \%$ compared to those that did not. Following two to four of the recommendations reduced risk by $44-48 \%$, while following only one recommendation was associated with a reduction of $11 \%$. The cancer prevention recommendations specifically related to alcohol, body fatness, and plant foods were the most significant in reducing postmenopausal breast cancer incidence. Those who met all three of these specific recommendations had over a $60 \%$ reduced risk of developing cancer. AICR estimates that approximately $38 \%$ of breast cancer cases alone could be prevented by adhering to these guidelines. ${ }^{28}$

A 2011 review by Pekmezi highlighted the evidence in support of diet and exercise interventions in cancer survivors. ${ }^{30}$ Targeted guidelines for cancer survivors issued by the American Cancer Society (ACS), WCRF, and the American College of Sports Medicine (ACSM) emphasize the importance of diet and exercise in preventing cancer and reducing the adverse effects of cancer and its treatment. ${ }^{4,30}$ Findings indicated that overall, physical activity interventions lead to improvements in fitness, strength, and quality of life. ${ }^{26}$ The guidelines also emphasize the importance of consuming a plant- 
based diet that focuses on fruits, vegetables and unrefined whole grains in order to reinforce the importance of weight management.

Trials targeting weight management often combine dietary interventions, such as those that encourage a low-fat diet plus increased produce intake with other modifiable lifestyle behaviors like physical activity. One study of 1,490 early-stage breast cancer survivors found greater survival rates in physically active women regardless of obesity when the women consumed higher amounts of fruits and vegetables (5 servings per day). ${ }^{31}$ Furthermore, a 2008 study suggested that group exercise classes did not impact dietary intake, but were effective in increasing physical activity levels among breast cancer survivors. ${ }^{32}$ A 2009 study of colorectal cancer survivors found that home-based approaches utilizing tailored print materials and/or telephone-based motivational counseling to promote fruit and vegetable intake and exercise did not have a significant impact on physical activity, but did lead to dietary improvements such as increased fruit

and vegetable consumption. ${ }^{33}$ In order to provide insight on how lifestyle modifications can impact health, there is a critical need for randomized controlled trials assessing the impact of physical activity and dietary interventions on cancer survival outcomes.

\section{Need for Targeted Nutrition Interventions}

Despite vast improvements in survival rates, survivors are still at increased risk for recurrence, developing new primary or secondary cancers, and post-treatment complications. Due to the effects of cancer treatment, genetics, and/or lifestyle factors, cancer survivors are also at a greater risk for premature mortality and morbidity. Comorbidities including osteoporosis, CVD, diabetes, and functional decline kill more 
survivors than cancer. ${ }^{10,34}$ Healthy lifestyle behaviors, encompassing consuming a plantbased diet, engaging in regular physical activity, and smoking cessation are of particular importance to survivors as they may slow the rate of functional decline. ${ }^{6,35}$

Demark-Wahnefried et al. documented that vigorous exercise paired with a diet low in fat and high in fruits and vegetables was associated with increased physical functioning among breast and prostate cancer survivors, especially elderly survivors. ${ }^{36}$ There is a growing body of evidence to support the role of exercise in modulating various mechanistic cancer pathways. ${ }^{6}$ It is well documented that physical inactivity, excessive energy intake, and excess adiposity contribute to an increased risk of cancer despite the scientific uncertainty surrounding how certain aspects of these factors specifically relate to cancer. ${ }^{4,6,27,35}$ Adopting a physically active lifestyle and consuming a plant-based diet is also endorsed by the ACS guidelines for survivors. ${ }^{1,4}$

Demark-Wahnefried also conducted a review in 2005 to summarize lifestyle changes that are pursued by cancer survivors post diagnosis in an attempt to reduce adverse treatment-related effects and comorbidities. In cancer survivors, obesity was related to both cancer recurrence and reduced quality of life. ${ }^{37}$ Is it well documented that weight loss is also proven to be beneficial in attenuating obesity-related problems such as hyperinsulinemia, dyslipidemia and hypertension, all common conditions affecting the survivor population. ${ }^{10,35,36,38}$ Mortality data indicates that CVD accounts for nearly half of noncancer-related deaths. ${ }^{39}$

Blanchard et al. documented that prostate, breast, and colorectal cancer survivors who exercise regularly, as well as those who practiced more than one healthful behavior 
(e.g., engaging in regular PA, consuming five or more servings of fruits and vegetables per day, avoiding smoking) had significantly higher levels of health-related QOL than those who only met one recomendation. ${ }^{11}$ Indeed, this study provides more evidence of the importance of targeting more than one lifestyle behavior for optimal cancer survivorship results. ${ }^{31}$

Inadequate dietary intakes and lack of physical activity are significant risk factors for chronic disease and cancer; hence, promotion of targeted lifestyle interventions among this vulnerable population is desperately needed. ${ }^{1,7}$ In order to encourage healthier behaviors, clinicians and healthcare providers must educate survivors on cancerrelated risk factors and offer personalized recommendations to reduce those risks via modifiable lifestyle behaviors. The period surrounding a cancer diagnosis is often referred to as a "teachable moment," when treating oncologists can gently encourage newly diagnosed clients to adopt healthier behaviors. The pivotal role that oncologists can play in health promotion is clear; yet studies show that less than $25 \%$ of physicians actually provide health promotion counseling to patients. ${ }^{9,10}$ In addition, a recent study found that less than $50 \%$ of physicians feel comfortable providing dietary advice to patients. $^{40}$

\section{Garden-Based Interventions}

Several studies in the past have been successful in evaluating the opinions, behaviors, and health perceptions of adult urban gardeners, though few focus on cancer

survivors. ${ }^{24,41,42}$ In healthy populations, urban gardening interventions offer an array of health benefits, including the promotion of social interactions as well as improved dietary 
intakes and physical activity. ${ }^{24,41,42,43}$ Gardening interventions have enhanced healthy behaviors in children, adults, and recently, elderly cancer survivors; however, the majority of existing studies focus on youth, low-income, and/or minority populations. Evidence consistently shows that garden-based nutrition education in schools or community gardens also improves fruit and vegetable consumption and their willingness to taste new produce in adolescents and children. ${ }^{12,18,19-23}$

Though evidence on garden initiatives in adults remains limited, the literature reports that gardening is associated with increased produce intake and physical activity as well as improved physical functioning and overall well-being. ${ }^{14,17,41,42}$ Johnson documented that delivery of locally grown fruits and vegetables to homebound seniors may be an effective way to increase fruit and vegetable consumption. ${ }^{44}$ In a later study, Chen et al. documented that older gardeners had better balance and gait speed, fewer chronic conditions, and less functional decline compared to control non-gardeners. ${ }^{17}$

Blair et al. conducted a 12-month mentored gardening intervention that paired 12 adult and child cancer survivors with certified Master Gardeners to evaluate fruit and vegetable consumption, PA, QOL, and physical function. ${ }^{24}$ Survey data were collected on dietary intake, PA, and QOL. Anthropometrics and physical functioning were also measured. Though no significant weight loss was reported, all of the adult survivors and $75 \%$ of parent-caregivers achieved two of three health behavior/function goals. These goals included an increase of $\geq 1$ fruit and vegetable servings/day, an increase of $\geq 30$ minutes/day of physical activity, and improvement in three out of four physical function measures. ${ }^{24}$ This novel pilot study demonstrates that improvements in physical 
functioning, fruit and vegetable intake, and physical activity can be achieved via comprehensive interventions such as mentored gardening programs for cancer survivors.

\section{Focus Groups}

Focus groups, the most widely used technique of qualitative research, ${ }^{45}$ can be defined as carefully planned sets of discussions designed to gain perceptions on a defined area of interest in a permissive, nonthreatening environment. ${ }^{46}$ According to the Handbook for Excellence in Focus Group Research, focus groups involve a small group of respondents guided by a skilled moderator into increasing levels of depth on the key levels of the research project. ${ }^{45}$ They help generate new ideas and gain insight on attitudes, beliefs, and emotional reactions. Focus groups can be used for both program development and evaluating existing programs.

Focus groups traditionally consist of eight to ten people, but smaller groups provide greater depth of response from participants. An optimal focus group is conducted in a quiet, relaxing environment among a homogenous target population of five to seven participants and lasts no more than two hours. ${ }^{46}$ Facilities with observation rooms and audio or video recording equipment are the standard for focus groups in the United States. The interviewer typically asks ten or fewer open-ended questions with clarifying follow-up questions. In order to encourage equal participation, it is recommended that group sessions consist of a homogeneous group of participants. The respondents' level of expertise, education, experience and characteristics may significantly affect responses to specific topics. ${ }^{45}$

Gardening Focus Group Studies 
A case study by Wakefield investigated the perceived health impacts of community gardening in Toronto, Ontario through participant observation, focus groups and in-depth interviews. ${ }^{41}$ Researchers visited the gardens almost daily in addition to attending garden meetings, canning workshops, harvest cooking events and community barbecues. ${ }^{41}$ Ten focus group sessions were held with three to nine participants per group, each lasting one to two hours. The question thread focused on the role of community gardening in the respondents' lives. In cases when it was not feasible to conduct focus groups, in-depth interviews were held. These were offered as an alternative to focus groups to boost participation from those who were not comfortable in a focus group setting. Focus groups were tape-recorded and transcribed verbatim, which formed the bulk of the data analysis, accompanied with field notes from the participant observation. The community gardens in this study were quite diverse, varying in both size and organization (including allotment gardens with individual plots, communally worked gardens, and gardens that offered employment). Similarly, participants came from highly diverse backgrounds.

The investigators found that participants perceived that the gardens impacted their health by improving access to fresh, wholesome foods. Having the opportunity to grow and eat culturally appropriate foods was seen as a valuable experience, especially since many of the culturally appropriate foods were typically extremely expensive and not widely available. Gardeners also reported increased physical activity. Furthermore, respondents reported improved mental health in terms of stress reduction and empowerment as well as a stronger sense of community pride and attachment. The 
gardeners identified several challenges to sustainability, mainly that of uncertainty related to urban redevelopment.

Gardeners also expressed concerns regarding personal safety, organization, lack of appreciation and the impact of the environment on the quality of the produce due to possibly contaminated soil and spoilage. These concerns exemplified the ability of community gardeners to understand the relationship between the quality of local environments and risks to their health that non-gardeners may fail to recognize. In order to better understand the potential for these urban gardens to enhance public health, more quantitative research is needed to determine the effectiveness of community gardens as health interventions.

A 2013 study by Lombard conducted focus groups in San Juan Country, New Mexico to assess Navajo perceptions, knowledge, and attitudes of garden-based wellness interventions in preventing type 2 diabetes (T2DM) and cancer. ${ }^{16}$ Due to poor access to nutritious foods, departure from traditional diets, and low levels of physical activity, the Navajo are at increased risk for T2DM and certain types of cancers. Southwest Native Americans have increased rates of stomach, gallbladder, kidney, myeloma, and liver cancers compared to non-Hispanic Whites. In addition, T2DM is becoming increasingly prevalent among the Navajo youth. ${ }^{16}$ Seven focus groups of 31 people were conducted to evaluate knowledge and attitudes regarding growing food locally. Researchers also assessed barriers and facilitators to participation in a garden project. Results from focus group discussions demonstrated that the participants were conscious of the prevalent health issues (namely obesity and diabetes) on the reservation. Participants viewed 
gardening as part of the return to a more traditional, healthy lifestyle that could help reduce the incidence of diabetes.

Barriers to growing food locally included issues with lease agreements, lack of available gardening space, time constraints, and overall lack of gardening knowledge. Several participants perceived a sense of urgency around issues related to diabetes in the community, especially given the high consumption of unhealthy foods, high risk lifestyles, and the increasing prevalence of diabetes in youth. Overall, the focus groups results suggest that gardening may not only help reduce the risk of diabetes and cancer by increasing produce intake, but may also improve community health among the Navajo. 


\section{Chapter 3: Methods}

The purpose of this study was to determine the perceptions of cancer survivors participating in an urban harvesting initiative. The perceptions and impact of receiving and utilizing the produce harvested during one growing season (June through August 2013) at the GOH was evaluated to inform future interventions aimed at improving overall adherence to the AICR's evidence-based guidelines for cancer survivorship. The results of this study provide insights into many reported positive health outcomes and some barriers of harvesting produce in an urban garden setting for cancer survivors. This chapter will discuss the methods of this study, including research design, subject selection, data collection, and data analysis. Approval for this study was obtained from the Human Subjects Institutional Review Board at The Ohio State University prior to conducting the study. The objectives of the study were as follows:

1. To identify positive outcomes, barriers and challenges of urban harvesting for cancer survivors.

2. To determine the impact harvesting at the Garden of Hope has on survivors' health perceptions.

3. To determine how produce harvested at the Garden of Hope is being used by the cancer survivors. 


\section{Research Design}

This study was conducted using a descriptive research design. Utilizing a series of open-ended questions and subsequent follow-up questions within focus groups, the benefits and barriers in receiving and utilizing the produce harvested at the $\mathrm{GOH}$ during one 3-month growing season were determined. The focus groups were audio-recorded and transcribed verbatim prior to being imported in Ethnograph (version 6.0, Qualis Research Associates, Denver, CO) for coding and analysis. Results of the focus groups will be used to inform JCFL on improving the GOH experience, to inform researchers on considering participant perceptions when developing future harvesting interventions, and to inform future recommendations targeted at improving adherence to the AICR's evidence-based guidelines for cancer survivorship.

\section{Focus Group Questions}

1. Tell me your thoughts about the Garden of Hope program.

- Do you believe the Garden of Hope was a positive experience?

- What barriers or challenges did you encounter throughout the program?

2. Did the Garden of Hope program impact your health in any way?

- Did you make any changes to your diet throughout the program?

- Did the program affect your level of physical activity?

3. Did you interact with anyone throughout the Garden of Hope program? Tell me about that experience.

- JamesCare staff

- Student dietetic interns 
- Other survivors

4. Tell me how you used the foods you harvested at the Garden of Hope.

- Did the produce harvested affect your shopping, cooking and eating habits?

- Were there any foods you harvested that you didn't know how to prepare or cook at home?

- Did you try any new foods as a result of the Garden of Hope program?

- Are these foods you will continue to eat?

5. Do you have any additional comments or concerns?

\section{Instrument Development}

Prior to participation in the focus groups, participants were asked to complete a confidential survey (Appendix C). The two-page supplemental survey included 11 nonidentifiable questions related to demographic information and basic cancer history. The survey was developed by a team of survey design experts and based largely upon the literature using a mix of new and validated questions. In order to assess food security, participants completed the USDA Economic Research Service's Six-Item Short Form of the Food Security Survey Model (FSSM) (Appendix D). ${ }^{47}$ Developed by researchers at the National Center for Health Statistics, this survey has reasonably high sensitivity, specificity and minimal bias in identifying food-insecure households compared to the 18item measure. The six-item scale provides a shorter yet still reasonably reliable substitute

for the 18-item or 10-item measures that are commonly used to assess food security. ${ }^{48}$ 


\section{Subject Selection}

Focus group participants were recruited via email distributed by the JCFL staff (key personnel) from an existing list of $\mathrm{GOH}$ participants (Appendix A). Interested participants were asked to reply to the email with date and time preferences for attending one of three scheduled focus groups. Once a reply was received, key personnel sent a second email with study details and a copy of the informed consent (Appendix B). This email stated that participants would be asked to sign a written consent form at the focus group meeting and complete a short survey. It also explained that all information would be kept confidential and reminded participants that they could choose not to respond to any given question and could discontinue participation at any point in time without adverse consequences. The email also explained that the focus group sessions would be audio recorded and would last approximately two hours. Key personnel sent a reminder email one week prior to the session. Survivors received a \$10 Kroger gift card for their participation.

\section{Data Collection}

The focus group questions were designed to elicit perceptions, attitudes and experiences related to harvesting produce at the GOH. Twenty-eight adult cancer survivors participated in one of three focus groups and no one who attended the focus groups refused to participate. The focus groups consisted of seven to twelve participants per group and were conducted in November 2013. They were held at The Stephanie Speilman Comprehensive Breast Center, which provided a comfortable, familiar environment and location for participants. Chairs were arranged in a circle to facilitate 
discussion.

A designated leader, who was familiar with the methodology and had previous experience conducting focus groups, led all discussions. Prior to the start of the focus groups, the leader handed each participant a copy of the consent form and an appropriate writing utensil. Participants completed the consent forms and were given the opportunity to ask additional questions pertaining to the study. Once signed consent forms were returned, the participants received the supplemental surveys that included nonidentifiable questions related to demographic information, basic cancer history, and a food security status questionnaire. The leader provided detailed information on the surveys and their intended use as well as detailed instructions for completion.

Participants were reminded they could refrain from answering any questions without consequence. Next, participants were instructed to complete the surveys and were provided ample time to do so. If any participant required assistance, the leader was readily available to help. Upon completion of the surveys, they were collected by the leader and placed in a sealed manila envelope.

All three focus groups were audio-recorded using a digital device to minimize recorder bias (2007-2009 Pulse Audio Smart Pens, Livescribe Inc., Oakland, CA). Survivors were made aware of the presence of the audio recording devices prior to beginning the interviews. The leader made sure to prompt feedback from all members and regulated the input from more talkative participants. A graduate assistant was present at all focus group to assist with data collection, transcribe the participants' conversations 
verbatim in Microsoft Word, and record observational notes of behaviors and interactions among members.

\section{Data Analysis}

Audio recordings from the three focus groups were transcribed in order to evaluate trends, observations, and common issues that developed throughout the discussions. The data for analysis consisted of the graduate student's verbatim transcriptions. The research team individually reviewed the data in print to determine the recurring themes and subthemes and then developed a codebook to reflect the themes that emerged from the data. They then compared coding schemes and achieved agreement on the thematic framework. Inter-rater reliability was checked and the code list was further refined to reflect changes. In order to establish inter-rater reliability, two researchers analyzed each transcript. Reliability was calculated as the number of agreements between the coders divided by the sum of the number of agreements and number of disagreements. Acceptable levels of variability were set at $85 \%$. Using two researchers to code the data minimized research biases, and the codes were reread within each category to confirm consistency.

The refined code list was used to code each data file electronically using Ethnograph (version 6.0, Qualis Research Associates, Denver, CO), a computer program that codes items of interest and facilitates with the analysis and quantification of qualitative data. ${ }^{49}$ The graduate student marked the lines of segments in Ethnograph containing quotes of interest with a corresponding code word from the code list. The text segments varied in length from one line to several paragraphs. After the original list of 
themes was coded, the subthemes were coded. They were then sorted by code words to facilitate analysis.

Descriptive statistics were used to define the study population on in terms of the following characteristics: age, ethnicity, gender, relationship status, cancer history, age of diagnosis, number and type of cancers, treatment status, and comorbidities. Frequency analyses were conducted to determine the rate of self-reported health conditions (hypertension, type 2 diabetes, fibromyalgia, high cholesterol, anxiety, depression, irritable bowl syndrome, asthma, polycystic ovarian syndrome, and mitral valve prolapse) in this cohort. Surveys were later coded and data was entered into Microsoft Excel (version 14.3.9). Responses to the FSSM were coded as affirmative or not affirmative according to the module's user notes. The sum of affirmative responses to the six questions in the survey is the household's raw score on the scale, which indicated the food security status on a scale of $0-6$, with low scores indicating high food security and high scores indicating lower food security. ${ }^{47}$ 


\section{Chapter 4: Results and Discussion}

\section{Results}

A total of 28 survivors participated in the focus groups. Table 4.1 details the subject characteristics and cancer history of participants. The majority of the participants were Caucasian $(78.5 \%)$, female $(89.3 \%)$ and not in treatment at the time of the study (78.6\%). The age range of all participants was 35-83 years and the mean age was 62 years. The most prevalent type of cancer was breast (53.5\%). None of the participants were smokers. One-fourth of the GOH harvesters reported a diagnosis of hypertension while $11 \%$ reported diabetes. Participants harvested at the GOH an average of 12 times throughout the season. Table 4.2 details the food security status of participants. Half of the participants were categorized as food secure and $17.9 \%$ were marginally food secure. One-fourth of the participants were found to have low food security and $7 \%$ had very low food security.

Four major overarching themes were identified from participant focus groups including: (1) perceptions of improved mental and physical health, (2) adherence to a plant-based diet and healthy modifications in cooking and meal planning, (3) greater sense of community and social support, and (4) challenges to harvesting. Summary data for the overarching themes found are described in Table 4.3. 


\begin{tabular}{lr}
\hline Variables & \\
\hline Age & $62.25(35-83)$ \\
Race & \\
$\quad$ Caucasian & $78.5 \%(\mathrm{n}=22)$ \\
African American & $10.7 \%(\mathrm{n}=3)$ \\
European-American & $3.6 \%(\mathrm{n}=1)$ \\
Polish-American & $3.6 \%(\mathrm{n}=1)$ \\
$\quad$ Latino & $3.6 \%(\mathrm{n}=1)$ \\
Gender & \\
Female & $89.3 \%(\mathrm{n}=25)$ \\
Male & $10.7 \%(\mathrm{n}=3)$ \\
Relationship Status & \\
Married & $53.6 \%(\mathrm{n}=15)$ \\
Widowed & $17.9 \%(\mathrm{n}=5)$ \\
Divorced & $10.7 \%(\mathrm{n}=3)$ \\
Living with partner & $10.7 \%(\mathrm{n}=3)$ \\
Single & $7.1 \%(\mathrm{n}=2)$ \\
Non-Smoker & $100 \%(\mathrm{n}=28)$ \\
Age of Cancer Diagnosis & $55.89(32-82)$ \\
Number of Cancers & $1.14(1-2)$ \\
Type of Cancer & \\
$\quad$ Breast & \\
Prostate & $53.5 \%(\mathrm{n}=15)$ \\
Lung & $7.1 \%(\mathrm{n}=2)$ \\
Ovarian & $7.1 \%(\mathrm{n}=2)$ \\
Colon & $3.6 \%(\mathrm{n}=1)$ \\
Mouth & $3.6 \%(\mathrm{n}=1)$ \\
Skin & $3.6 \%(\mathrm{n}=1)$ \\
Thyroid & $3.6 \%(\mathrm{n}=1)$ \\
Non-Hodgkin's Lymphoma & $3.6 \%(\mathrm{n}=1)$ \\
No Response & $3.6 \%(\mathrm{n}=1)$ \\
& $14.3 \%(\mathrm{n}=4)$ \\
\hline & \\
\hline & \\
& \\
& \\
& \\
&
\end{tabular}

Table 4.1 Subject Characteristics of Cancer Survivors Harvesting at an Urban Garden

Continued 
Table 4.1 (continued)

\begin{tabular}{lr}
\hline Treatment Status & \\
\hline Currently in Treatment & $7.1 \%(\mathrm{n}=2)$ \\
Not in Treatment & $78.6 \%(\mathrm{n}=22)$ \\
No Response & $14.2 \%(\mathrm{n}=4)$ \\
Other Diseases & \\
Hypertension & $25.0 \%(\mathrm{n}=7)$ \\
Diabetes & $10.7 \%(\mathrm{n}=3)$ \\
Fibromyalgia & $3.6 \%(\mathrm{n}=1)$ \\
High cholesterol & $3.6 \%(\mathrm{n}=1)$ \\
Anxiety & $3.6 \%(\mathrm{n}=1)$ \\
Depression & $3.6 \%(\mathrm{n}=1)$ \\
IBS & $3.6 \%(\mathrm{n}=1)$ \\
\hline
\end{tabular}

\begin{tabular}{ll}
\hline Food Security Status & \\
\hline High food security & $50.0 \%(\mathrm{n}=14)$ \\
Marginal food security & $17.9 \%(\mathrm{n}=5)$ \\
Low food security & $25.0 \%(\mathrm{n}=7)$ \\
Very low food security & $7.1 \%(\mathrm{n}=2)$ \\
\hline
\end{tabular}

Table 4.2 Food Security Status of Cancer Survivors Harvesting at an Urban Garden 


\begin{tabular}{|c|c|}
\hline Themes & Participant Quotes Supporting Themes \\
\hline \multicolumn{2}{|l|}{ Improved Health } \\
\hline Mental Health & $\begin{array}{l}\text { It completely made a huge difference in just how I felt, your } \\
\text { outlook, your thoughts, your physicality, just everything about it. } \\
\text { It was really uplifting in a lot of different ways. It was } \\
\text { noticeable. } \\
\text { I felt I had a very direct and immediate connection with the time } \\
\text { I spent out there. It was me time and I could just come out to the } \\
\text { farm and it was very relaxing but also very real...it doesn't get } \\
\text { any more real than picking own food. That part of it, I thought, } \\
\text { was very nutritional to my soul. } \\
\text {...not only mentally but physically, it really brought not only } \\
\text { peace for her but also for the stress as a caretaker. Just getting } \\
\text { out there and picking, and even helping others pick, getting your } \\
\text { hands dirty, really mentally helps some of that stress get into the } \\
\text { land and not in your heart and your body. I just felt really good } \\
\text { being there, it was fun to pick things...it was kind of spiritual in } \\
\text { a way. } \\
\text { I learned a lot and it was very spiritual for me, too. I grew up and } \\
\text { we always had a garden, and my mom canned. We all helped. } \\
\text { To me, the smell of the earth, the wet earth, it's just the most } \\
\text { heavenly fragrance for me. I really enjoyed that. } \\
\text { For me, the other aspect of not only enjoying the vegetables is } \\
\text { there's definitely a spiritual connection that I experienced going } \\
\text { out to the garden because I grew up with a father who gardened } \\
\text { for a hobby, and so, the healing was much broader than eating } \\
\text { vegetables. } \\
\text {...you're standing here, you know you're in the middle of this } \\
\text { big city, but you're on this oasis, ya know, and you can just } \\
\text { block everything out. And it was, it was very spiritual. } \\
\text { to }\end{array}$ \\
\hline
\end{tabular}

Table 4.3 Overarching Themes from Participant Focus Groups Determining Health Perceptions of Cancer Survivors Harvesting at the Garden of Hope

Continued 
Table 4.3 (continued)

\begin{tabular}{|l|l|}
\hline Physical Health & $\begin{array}{l}\text { I did, because it made me go. Today is the day I get fresh } \\
\text { veggies so I made myself get up and go. Of course I have a } \\
\text { husband, a caretaker to drive me there. I got out because this is } \\
\text { mine. I got out and I was walking along, otherwise I could have } \\
\text { been home laying on the couch or sitting on the couch but I was } \\
\text { actually walking around the garden and picking. It kind of } \\
\text { pushed me outside. }\end{array}$ \\
$\begin{array}{l}\text { Feeling more focused, feeling energetic versus feeling like I } \\
\text { could lie on the couch for days. Ya, I think it helped a lot in so } \\
\text { many ways; and maybe just because I'm more tuned into my } \\
\text { physiology. Ya, I would say it made a huge difference for me. }\end{array}$ \\
$\begin{array}{l}\text { Ifresh vegetables made me have more energy. Like Ho said, } \\
\text { I'm more able to focus. I can see more, better, as far as being in } \\
\text { college myself I can see better grades. }\end{array}$ \\
$\begin{array}{l}\text { I think that's the takeaway for what I learned from the garden } \\
\text { because... that's the best question because I did feel physically } \\
\text { different. I felt lighter; and I felt like I could skip. I mean it was } \\
\text { weird, it was noticeably weird because I didn't expect that... }\end{array}$ \\
$\begin{array}{l}\text { I enjoyed the physical aspect of the time I went out. I kind of } \\
\text { have a hard time walking, so walking the fields was a little more } \\
\text { challenging for me, but the bending over and picking that got me } \\
\text { some more activity. } \\
\text { But I was tired this summer, and there were times when my } \\
\text { daughter would call and say' let's go to the garden' and it meant I } \\
\text { got off the couch and I moved around and that night I actually } \\
\text { cooked and so I moved around a little then. So really, when you } \\
\text { are tired it gives you a reason that you need to get up and } \\
\text { function. }\end{array}$ \\
\hline
\end{tabular}

Continued 
Table 4.3 (continued)

\begin{tabular}{|c|c|}
\hline Improved Nutrition & \\
\hline $\begin{array}{l}\text { Adherence to a Plant- } \\
\text { Based Diet }\end{array}$ & $\begin{array}{l}\text { We made a ton of curries, ya know. We were cooking } \\
\text { vegetables different ways and putting them over spaghetti squash } \\
\text { that we bought or had frozen. We just ate so majestically this } \\
\text { summer because of the garden. It was just so wonderful. } \\
\text { We're moving toward more of a vegetarian diet. I will not say } \\
\text { we've given up-- we still like chicken, my husband still likes } \\
\text { turkey, we like fish... but I try to do as you do K, which is ya } \\
\text { know can we just have a bunch of cooked vegetables and ya } \\
\text { know then maybe a fruit salad and make that a meal.... } \\
\text { It benefitted me because I learned to actually make more } \\
\text { vegetable dishes than I usually do. Most of the time we were } \\
\text { eating vegetable dishes instead of meats, which helped. It also } \\
\text { got my husband back to eating vegetables. } \\
\text { It helped us increase the number of vegetables we eat, even to } \\
\text { the point where as we plan our Thanksgiving holiday meal, it } \\
\text { will be more vegetarian than it has been before... this really } \\
\text { reinforced and provided quality of vegetables that we couldn't } \\
\text { get elsewhere. I mean coming home with a bag of stuff from this } \\
\text { week and what are we gonna do with that. We don't want to sit } \\
\text { and wait...we want to get into it. It was a really delightful kind } \\
\text { of experience. } \\
\text { I too really looked forward to going there when I could, and we } \\
\text { ate lots of salads, loaded salads and things because of that. It } \\
\text { really helped me to focus on vegetables. }\end{array}$ \\
\hline
\end{tabular}

Continued 
Table 4.3 (continued)

\begin{tabular}{|c|c|}
\hline $\begin{array}{l}\text { Healthy Modifications } \\
\text { in Cooking and Meal } \\
\text { Planning }\end{array}$ & $\begin{array}{l}\text { I got back to it (canning and preserving), which for a long time } \\
\text { wasn't part of something I'd been doing. That's another joyous } \\
\text { thing to get back to something that I'd done before and really } \\
\text { enjoyed. } \\
\text { It really just became a big part of my summer. Coming down } \\
\text { here and getting produce and structuring my diet around that } \\
\text { became the focus of the week. I couldn't wait to come again, get } \\
\text { something else and just be home and wash it and put it away and } \\
\text { kind of plan my meals and everything. It just really, really made } \\
\text { a huge difference in how I ate through the summer. } \\
\text { It became the focus of my diet. It was the core around which I } \\
\text { structured my other protein and foods; and I couldn't say enough } \\
\text { good things about it. } \\
\text { It replaced a lot of the snack foods we eat at night because it's } \\
\text { easier than going and grab a cracker or whatever. We had like } \\
\text { cucumbers or onions or Di showed me how to make a salad with } \\
\text { cucumbers, tomatoes and onions. We had something simple or if } \\
\text { at a certain time we weren't feeling up to cooking something, we } \\
\text { were able to make full vegetable salad. We had some kind of } \\
\text { energy there in it. } \\
\text { And as I said before, just getting produce forced me to invest a } \\
\text { little more time in meal planning and what it is I was making, } \\
\text { cuz before we kind of ate to survive. So having all this produce, } \\
\text { I'm suddenly looking for recipes for different dishes to make or } \\
\text { different breads to bake. So it forced me to take a closer look at } \\
\text { what we we're eating and how we were preparing food and } \\
\text { things of that nature. It was a very good experience for both of } \\
\text { us. } \\
\text { I stopped eating boxed food and I stopped eating lots of grains } \\
\text { and processed stuff and my body was so happy and I could tell. I } \\
\text { was like wow... this is what happens! It was euphoric, really. } \\
\text { And that starts you on a path, like you need that step, that spark, } \\
\text { and then you just embrace everything else. }\end{array}$ \\
\hline
\end{tabular}

Continued 
Table 4.3 (continued)

\begin{tabular}{|l|l|}
\hline Support & \\
\hline \multicolumn{1}{|c|}{$\begin{array}{c}\text { Creater Sense of } \\
\text { Support }\end{array}$} & $\begin{array}{l}\text { And this is a community thing, this little farm...from Glenn on } \\
\text { to the students...and people who come with their caretakers who } \\
\text { are having just as much fun as people who are physical } \\
\text { survivors. The community is a critical part of it. I never thought } \\
\text { of it as my place of feeling it's my place, but I suppose in some } \\
\text { ways it is. So that community feature to it permeates } \\
\text { everything...it's critical to it. }\end{array}$ \\
Going to the garden you were part of a bigger circle of people. \\
Well I think there's a lot of compassion in doing gardening with \\
others that share something in common. \\
$\begin{array}{l}\text { I enjoy being in the sun and I do enjoy meeting everyone at the } \\
\text { garden. There were times when I would pick what I went to get } \\
\text { or to see what I could add to mine and just stay, just walk around } \\
\text { the garden because I knew DG would show up or other DG } \\
\text { would show up and we would stop and talk and just stand there } \\
\text { and absorb each other's energy and the conversation. It's a } \\
\text { wonderful place to meet new people and share ideas. }\end{array}$ \\
$\begin{array}{l}\text { It's a health, stress reducer, just to be there, not necessarily just } \\
\text { the plants, but the people too. }\end{array}$ \\
$\begin{array}{l}\text {..it was really beneficial, I thought, to have students be part of } \\
\text { this activity...it really was very helpful. They were young and } \\
\text { vital and they knew stuff; and they plunged right in and became } \\
\text { part of the community. }\end{array}$ \\
$\begin{array}{l}\text { I loved the students being there because whether you could get } \\
\text { down and pick or not, the students were going out further into } \\
\text { the garden. And they'd say hey, there are plenty of peppers here. } \\
\text { And they would pick some peppers and bring them to people } \\
\text { who weren't venturing so far out. Ya know, it's nice to have } \\
\text { youth. }\end{array}$ \\
\hline
\end{tabular}

Continued 
Table 4.3 (continued)

\begin{tabular}{|c|l|}
\hline Challenges & \\
\hline Harvesting & $\begin{array}{l}\text { It would be better if we had more set days, more time, being as } \\
\text { large it is. And all of us work and stuff and we have to rush to } \\
\text { get here or there, so it needs to be done at better set of times. } \\
\text { I too felt the windows of time were too few and rather narrow, } \\
\text { especially if dealing with traffic to get to the garden and to get } \\
\text { home. }\end{array}$ \\
$\begin{array}{l}\text { I would recommend also to extend the hours because there was } \\
\text { twice when I was on my way and couldn't get there because there } \\
\text { was an accident. I'm coming from Dublin and an hour later I'd } \\
\text { have to turn around and come home... }\end{array}$ \\
\hline $\begin{array}{l}\text { Ya know, I think the biggest thing I'm frustrated about and I } \\
\text { have been for a long time is when I go buy produce, you have to } \\
\text { literally use your produce in three or four days or the stuff goes } \\
\text { to crap. When I went to that garden, I was able to hold on to that } \\
\text { because it's fresher... }\end{array}$ \\
$\begin{array}{l}\text { I'm beginning to think that the quality of food in the grocery } \\
\text { store is starting to go down because when I stopped at the } \\
\text { garden, everything was very fresh. It all lasted. }\end{array}$ \\
$\begin{array}{l}\text { I just felt like, and I have to go to the store and eat that stuff } \\
\text { (laughing)! I walked through the produce department like, oh my } \\
\text { god, you poor people that have to come here, because I don't } \\
\text { know what they put on it. It's been picked who knows how many } \\
\text { days ago. It almost distorted my view of produce department } \\
\text { which I used to love... }\end{array}$ \\
$\begin{array}{l}\text { So I think, I can tell a difference from summer to now, I mean } \\
\text { this fall, I don't feel like I'm skipping because I don't have all that } \\
\text { produce so I have to struggle to find that and put it in my diet. }\end{array}$ \\
$\begin{array}{l}\text { Now that it's autumn and I'm using stuff from the store, I'm not } \\
\text { happy with what I'm making. The choices are slimmer in terms } \\
\text { of how long the food's gonna last. It was lovely to get a } \\
\text { cucumber and know that it would last for a couple of weeks. } \\
\text { Now I get a cucumber and it's gone in three days. }\end{array}$ \\
\hline
\end{tabular}




\section{Discussion}

The purpose of this study was to determine the perceptions of cancer survivors participating in an urban harvesting initiative. These findings provide insight to better understand the health perceptions associated with harvesting as well as how adherence to AICR's guidelines for cancer prevention and survivorship could be improved. Four major overarching themes were identified from participant focus groups including: (1) perceptions of improved mental and physical health, (2) adherence to a plant-based diet and healthy modifications in cooking and meal planning, (3) greater sense of community and social support, and (4) challenges to harvesting. These primary themes encompass the key findings of the focus group questions as well as reveal the results of the study's objectives. All of the survivors expressed a sincere appreciation and sense of gratitude for the $\mathrm{GOH}$ experience during the focus group discussions.

\section{IMPROVED HEALTH}

\section{Mental Health}

Consistent with the work of others, our results indicate that harvesting had a therapeutic effect on the participants ranging from enhanced spirituality, socialization, reduced stress, and overall improved well-being. ${ }^{13,50-53}$ Gardening has been traditionally associated with stress relief and recovery from daily life hassles, ${ }^{53}$ and our results indicated that harvesting vegetables in an urban environment with other cancer survivors served as a much-needed distraction from the stress of living with cancer. Because of their reported increased produce intake, the survivors described feeling psychologically better about doing something good for their mind and body. The excitement of picking 
new vegetables, trying them in different recipes and sharing experiences with other survivors added to the perceived positive impact on mental health as well. Van den Berg documented via measures of cortisol levels and self-reported mood that compared to the control activity of indoor reading, outdoor gardening promoted stronger recovery from stress. ${ }^{53}$ Of note, these studies address the outcomes associated with gardening, rather than harvesting as in our study. Being in direct contact with nature or a natural environment has also been associated with reduced mortality and morbidity from stressrelated diseases and faster recovery from acute and chronic stress. ${ }^{54}$ Though previous studies have reported the benefits of a garden setting on positive mental health and stress reduction, ${ }^{13,50,52,53}$ few are specific to cancer survivors and harvesting. ${ }^{24}$

In addition to improvements in mental health, the $\mathrm{GOH}$ also enhanced the participants' psychological well-being by providing something unique to which they could belong. Survivors felt a strong sense of responsibility and commitment to the group. Participants expressed appreciation for garden volunteers and for the supportive environment they created at the garden. The healing process for the survivors was enhanced by the social support at the GOH. Studies have documented the connection between social support in a garden setting and improvement in perceptions of well-being. ${ }^{13,50}$ The GOH also enabled participants to revisit fond memories, often including sentiments of close family ties, which enhanced their GOH experience.

Our results indicate that being so physically close and mentally connected to nature within a big city engendered a newfound sense of spirituality and connection to the soil and earth, which is consistent with previous studies documenting the stress-reducing, 
restorative powers of nature. ${ }^{51,54,55}$ Hartig et al. documented that walking in a nature reserve initially led to blood pressure change that signified greater stress reduction than that afforded by walking in the urban surroundings. ${ }^{55}$ Being in contact with nature has also been associated with reduced mortality and morbidity from stress-related diseases and faster recovery from acute and chronic stress. ${ }^{54}$ The strength and conviction of the perceived therapeutic and spiritual effects of the $\mathrm{GOH}$ was striking and has been previously documented. ${ }^{50,56}$ Heliker et al. reported improvements in psychological wellbeing and spiritual benefits that transcended cultural boundaries after a structured gardening intervention. ${ }^{50}$

\section{Physical Health}

Our results indicate that harvesting increased reported physical activity levels, which is consistent with previous studies documenting the physical benefits of gardening. ${ }^{17,24,34}$ Blair et al. documented that measures of physical function had the largest improvements in a mentored vegetable gardening intervention, surpassing produce intake and quality of life. Though our study did not evaluate physical function or fall risk, gardening in older adults has the potential for reducing fall risk and improving balance. ${ }^{17}$ The GOH provided the survivors a means for engaging in regular physical activity that they otherwise would not have had. For many survivors, harvesting increased walking, bending, and carrying. Participant responses indicated that these physical activity successes were linked to feelings of accomplishment, improvements in mental focus, increased energy and overall vitality.

All of the survivors were very grateful and appreciative for the opportunity to 
harvest at the GOH since post-treatment fatigue often prevented them from planting and maintaining their own gardens at home and contributed to a decrease in their physical activity levels. Many participants reported that harvesting at the GOH encouraged them to become more physically active. Furthermore, there were widespread reports that the garden energized them in a way that incentivized them to keep going back. Several participants felt a newfound sense of energy from the fresh produce that made them feel better, physically.

Because cancer survivors are at an increased risk for chronic diseases, physical activity is critical to reduce risk in this vulnerable population. ${ }^{4,6,9,27,35}$ The AICR guidelines for cancer prevention recommend lifestyle interventions that promote engaging in regular physical activity in order to slow down the progression of cancerrelated complications and to help maintain a healthy body weight. ${ }^{4-6}$ Regular physical activity is associated with higher levels of physical functioning and physiological stability in older cancer survivors. ${ }^{14,34}$

\section{IMPROVED NUTRITION}

\section{Adherence to a Plant-Based Diet}

The GOH gave cancer survivors access to a bountiful harvest of fresh vegetables and herbs throughout the summer, which led to an increase in overall produce consumption. Many survivors reported a newfound enthusiasm for consuming the plant products that they had manually harvested. Harvesters shared that they found themselves eating greater quantities of produce simply because the fresh vegetables tasted so superior One participant described the garden experience as "euphoric" as she explained how the 
GOH served as the "spark" she needed to start her on the path to embracing wellness. Participants also reported experimenting with unfamiliar vegetables such as kohlrabi that were previously avoided. They added that they now plan to purchase more of these vegetables and incorporate them into their diet. The willingness to taste new produce coupled with improved fruit and vegetable consumption following garden-based interventions in children and adolescents has been well documented in the literature. ${ }^{12,18,19-23}$ It is evident that interventions combining gardening activities with a nutrition education component enhance these positive effects. ${ }^{12,18,19-23}$ In addition to increased fruit and vegetable intake, McAleese and Rankin reported significant increases in vitamin $\mathrm{A}$, vitamin $\mathrm{C}$, and fiber intake following a garden-based nutrition education program in adolescents. ${ }^{22}$

The GOH harvesters consistently reported greater produce intake aligning with AICR's evidence-based dietary recommendations to consume a primarily plant-based diet. In addition to increasing their overall dietary produce intake, the $\mathrm{GOH}$ also encouraged harvesters to begin planning their meals around the produce harvested each week at the GOH. It is well documented that adopting a more plant-based diet not only reduces the risk of chronic disease, but may also lower body mass index, blood pressure, $\mathrm{HbAlc}$, and cholesterol levels. ${ }^{57}$ Furthermore, evidence links fruits and vegetables and their plant constituents such as fiber, antioxidants and other phytochemicals to achieving and maintaining a healthy weight and reducing the risk of cancer diagnosis and recurrence ${ }^{58}$ Interestingly, the GOH appeared to encourage greater adherence to AICR's guidelines simply by providing access to free produce. Studies have documented the 
connection between improved access to fresh produce and increased fruit and vegetable intake in homebound low-income seniors, disadvantaged communities, and children, but few in cancer survivors. ${ }^{19-23,44,59,60}$

In addition to attenuating the risk of developing comorbidities, consuming a primarily plant-based diet may curb obesity in the cancer survivor population ${ }^{57}$ In cancer survivors, obesity is highly correlated to both cancer recurrence and reduced quality of life. ${ }^{37}$ One-fourth of the GOH harvesters reported suffering from hypertension while $10.7 \%$ suffered from diabetes. Is it well documented that weight loss is proven to be beneficial in attenuating obesity-related problems such as hypertension, a common complication in the survivor population. ${ }^{10,35,37,38}$ Survivors also expressed an appreciation for the way in which the GOH put recommendations into action: "You listen to the doctors and you listen to the dietitians and everything and they say you have to eat better-well, this is what they're doing. They're putting it out there for us so in a lot of ways it is great. And the other hospitals...they're talking but they're not walking." Harvesters felt that the GOH provided them with the combination of education (dietitian and interns) in an environment (garden) that enhanced their understanding of application of the guidelines. Harvesting fresh produce was a cost-effective and enjoyable method of translating dietary guidelines into practice and may prove to be a novel intervention for many cancer survivors.

\section{Healthy Alterations in Cooking and Meal Planning}

The GOH also positively impacted how the participants cooked and prepared food at home. Many survivors commented that the abundance of garden produce inspired them 
to prepare vegetables in new and exciting ways. Harvesting vegetables at the GOH encouraged participants to seek out new healthy recipes and cook more at home in order to incorporate the produce into each meal. They were very appreciative of the recipes handed out at the garden as well. Several survivors commented that an abundance of produce forced them to learn how to cook more vegetable dishes than they normally would, and this positively influenced not only the survivors' health, but also the health of their families. Many noted that the garden helped their spouses increase their vegetable intake as well since they were cooking a more plant-based diet. Furthermore, survivors with grandchildren commented on the joy they felt watching the children begin to understand where food truly comes from and enjoy the experience of trying new foods.

The GOH became an integral part of meal planning as the participants structured their weekly meals around the produce they harvested at the garden. Many participants shared that coming home with an abundance of produce encouraged them to be more creative with meal planning and recipes. The GOH also encouraged survivors to take a closer look at the foods they were eating and invest time into carefully planning out how to make the most out of every vegetable without wasting. For example, participants were proud to share that because of the $\mathrm{GOH}$, they began drinking green smoothies with the kale and spinach they harvested. These healthy alterations in cooking and meal planning positively impacted the survivors' perceptions of health by encouraging greater adherence to a plant-based diet as recommended for cancer prevention and reduced risk of disease.

The garden provided the means to assist participants with shifting their focus 
toward healthy whole foods and away from unhealthy processed foods loaded with added sugar and sodium. Replacing high fat, high sodium, less nutrient dense foods with fresh produce in accordance with the AICR guidelines was another positive outcome reported. Several participants commented that the produce replaced their less healthy, processed snack alternatives throughout the garden season: "I stopped eating boxed food and I stopped eating a lot of grains and processed stuff and my body was so happy and I could tell...it was so easy not to eat junk food because why would I do that? I've got a zucchini sitting on the counter that I need to do something with tonight for dinner, and your body just really embraces that food." Others reminisced about the fresh cucumbers and tomatoes that they frequently snacked on throughout the summer instead of ice cream to satisfy their sweet cravings.

Access to a bountiful harvest encouraged the survivors to engage in healthy lifestyle behavior changes by impacting the way in which they prepared and preserved food at home. Several harvesters revisited previously retired cookbooks in order to find past recipes for preserving the produce. Others shared that they purchased books on canning and making relish, canned tomato sauce, and homemade ketchup. One participant dug out her old food dehydrator to make apple chips. Whether they began reading old cookbooks, exploring canning or dehydrating, many survivors reported engaging in healthier habits solely because of the $\mathrm{GOH}$ experience.

\section{SUPPORT}

\section{Greater Sense of Community and Social Support}

The GOH was far more than a place to obtain produce. Over the growing season, 
it became its own small support community — an outdoor support group where the cancer survivors could harvest, connect with one another, and share their common experiences. The importance of gardening as a venue for community engagement has been well documented. ${ }^{41,42}$ The garden often served as a community meeting place for survivors, which led to non-garden related discussions that fostered social health. Many survivors commented that the positivity of the garden experience and subsequent support expanded well beyond the nutritional aspect of the garden in unexpected ways, including the social networking experience with other cancer survivors: "I thought it was just wonderful because I didn't have to do much but come and talk to people and be available and support, and I thought it was wonderful." A study by Tse assessed the therapeutic effectiveness of an indoor gardening program in enhancing socialization, life satisfaction, social networking and reducing loneliness of among elderly nursing home residents. ${ }^{13}$ Participant interviews revealed significant improvements in life satisfaction and social network and a significant decrease in perception of loneliness. Our survivors reported similar benefits, including being "part of a bigger circle of people" at the GOH.

A sense of gratitude and appreciation for the volunteers who managed and maintained the garden was a common thread throughout the focus groups. Many survivors commented on the incredible gardening knowledge, overall support and generosity of the head farmer, Glenn. The survivors especially enjoyed the seedlings Glenn gave them at the beginning of the season and felt they served as a reinforcement of the GOH experience.. Many participants also commented on Glenn's generosity in donating such an immense amount of time to maintaining the GOH throughout the 
season. Survivors were also extremely appreciative of the countless hours put forth by the JamesCare staff and volunteers. This included checking in the survivors, guiding them throughout the garden, providing sunscreen and other gardening tools, and reminding them about other JCFL classes and offerings.

Lastly, participants were extremely thankful for the youth, energy, knowledge and enthusiasm of the dietetic students: "It was really beneficial, I thought, to have students be part of this activity...they were young and vital and they knew stuff; and they plunged right in and became part of the community." They also appreciated learning about new recipes and nutrition facts as well as how to use the produce in unique ways. One survivor commented that the students were always willing to go out of their way to enhance the garden experience for the survivors:" I loved the students being there because whether you could get down and pick or not, the students were going out further into the garden. And they'd say hey, there are plenty of peppers here. And they would pick some peppers and bring them to people who weren't venturing so far out. Ya know, it's nice to have youth."

\section{BARRIERS}

Scheduling

Conflicts with scheduling and limited availability of picking times was a common barrier discussed during the focus groups. Though JCFL attempted to include a majority of survivors based upon previous availability surveys (weekday morning, weekday evening and weekend), the harvest times from the previous year were not controlled so most of those reporting conflicts had no limitations previously. Many survivors 
commented that the windows of time were too narrow given conflicts with work, unpredictable traffic and weather conditions. Some participants expressed a desire for longer harvesting sessions. Survivors also voiced that they would appreciate a greater variety of produce, more harvesting tools, more education materials, more information regarding proper harvesting and storage, and more recipes.

Previous gardening studies have documented time constraints as a barrier to gardening. ${ }^{16,41}$ Other commonly cited barriers in previous community gardening studies have included lack of available gardening space, concerns about personal safety, organization, and overall lack of gardening knowledge. ${ }^{16}$ Because the GOH wasn't a community garden and the survivors were harvesting rather than gardening, the barriers in this study differ from traditional urban gardening barriers.

\section{Sustainability}

One common area of frustration focused on the disappointment with grocery store produce after growing accustomed to the freshness of the $\mathrm{GOH}$ produce. Participants reported dissatisfaction with the taste, textures, quality and freshness of supermarket produce after the harvest season ended: "Now that it's autumn and I'm using stuff from the store, I'm not happy with what I'm making. The choices are slimmer in terms of how long the food's gonna last. It was lovely to get a cucumber and know that it would last for a couple of weeks. Now I get a cucumber and it's gone in three days." Other participants emphasized suspicions related to preservatives and nutritional value of the supermarket produce since it rotted so much more quickly than the GOH produce. It has been well documented that product quality, whether real or perceived, is a main driver of consumer 
interest in fruits and vegetables and can greatly impact a person's desire to eat fresh produce ${ }^{61,62}$ Glanz et al. reported that taste preferences and nutrition are two of the greatest predictors of fruit and vegetable intake; however the discrepancy between produce from a grocery store versus a garden or farmer's market was not examined. ${ }^{62}$

These sentiments may certainly impact long-term sustainability of adhering to a plant-based diet. Several participants reported difficulty maintaining a healthier intake when the grocery store produce was perceived as inadequate and tasteless. The survivors' apparent distortion of grocery store produce was an unforeseen barrier to maintaining a plant-based diet. It may have been beneficial to educate survivors on the health benefits of canned or frozen produce in order to combat the avoidance of produce at the grocery store and to promote the maintenance of a plant-based diet. This may be especially useful in the months following the garden when the late spring and summer vegetables they enjoyed at the garden are no longer in season.

\section{Food Security}

Though one-fourth of the participants were found to have low food security and $7 \%$ had very low food security, very few participants commented on whether having access to free produce at the GOH benefitted them financially. Nonetheless, the GOH provides a means for increasing vegetable intake for those individuals who would not normally be able to afford to do so. Some studies suggest that socioeconomic status may be the most significant determinant of prognosis and survival. ${ }^{63-65}$ Even for insured and fully food-secure survivors, the cost of active treatment can be exorbitant. ${ }^{66}$ These financial burdens on cancer survivors and their caretakers can lead to food insecurity, 
which is often characterized by competing demands for limited resources that favor immediate priorities in lieu of long-term health and wellness ${ }^{67}$ Connecting food insecure survivors with local social services and supplemental food sources is critical.

There is a broad body of evidence suggesting that high cost and limited access to produce have been associated with lower intake of fruits and vegetables in low-income individuals. ${ }^{59}$ A 2010 study by Johnson et al. demonstrated that providing access to produce by home delivery of fruits and vegetables to low-income seniors is an effective way to increase fruit and vegetable consumption. ${ }^{44}$ Low-income individuals are more likely to increase their fruit and vegetable intake when incentives such as coupons or free access improve affordability ${ }^{68}$ A study by Anderson evaluating the Michigan Farmers' Market Nutrition Program demonstrated that combining education on the use, storage, and nutrition value of fruits and vegetables with coupons to maximize affordability had the largest effect fruit and vegetable consumption in low-income individuals. ${ }^{68}$

\section{Limitations}

Though the results of improved perceptions of health, nutrition, and community are encouraging, there are several limitations to consider. First, the study had a relatively small sample size $(\mathrm{n}=28)$. A larger controlled trial would be beneficial in further evaluating the efficacy of urban harvesting studies. Another limitation that may have introduced bias was having a dietetic student volunteer from the garden present at the focus group discussions. Although the student sat in the back to transcribe and observe, participants may have felt limited in what they could divulge and may have been guarded with their answers due to familiarity with the student. 
Though the average number of garden visits per season was twelve, some participants reported only visiting the garden once or twice. This limited exposure to the harvests may have influenced their responses. Additionally, some survivors had harvested with fewer time restrictions the previous year and therefore had differing views regarding barriers in scheduling. The study would have benefited from dividing those who harvested the previous year into separate focus group cohorts as to not influence the responses of first year participants. Further studies identifying the positive outcomes and the challenges in cancer survivors harvesting at an urban garden are needed to either support or refute the findings of this study.

\section{Implications for Practice and Future Research}

The results of this study provide preliminary support for positive perceptions of produce intake, mental and physical health, and community support for cancer survivors harvesting at an urban garden. The GOH provided access to fresh vegetables and herbs that may have not otherwise been purchased by the participants. The reported increase in produce consumption is promising as evidence-based scientific guidelines consistently recommended that cancer survivors adopt a primarily plant-based diet in order to prevent cancer reoccurrence and reduce the risk of future comorbidities.

Recommendations for future studies include assessing the survivors' dietary intake, physical activity, physical function and measures of mental health at baseline in order to have a pre/post harvesting comparison. Using valid methods to quantify biomarkers of exposure to dietary intake in addition to obtaining objective measures of physical function and mental health might be useful in confirming self-report 
improvements in perceived health. Furthermore, assessing body mass and indices of health (blood pressure, lipids, blood glucose, etc.) prior to the study and at the end of the intervention would be helpful in determining if a harvesting intervention improves biomarkers of health. It may also be helpful to provide more education on the guidelines for cancer survivorship and the importance of adhering to the recommendations.

Involving cancer survivors in the actual planting and gardening process versus strictly harvesting may be beneficial in optimizing physical activity and enriching the overall harvesting experience as well. Participants expressed interest in giving back to the GOH by helping with the planting, garden maintenance, or volunteering at the check-in booth. Interventions featuring more gardening activities may have greater potential for sustainability. Randomized controlled trials would be beneficial in order to evaluate the efficacy and sustainability of vegetable gardening and harvesting interventions.

The participants felt that more recipes and general harvesting education would have greatly benefitted their experience. Some participants expressed confusion with how to incorporate new produce into their diet. Offering educational harvesting handouts and classes that feature plant-based diet education, food safety, food storage and preservation tips may enhance the harvesting experience and improve outcomes. A website may also serve this purpose. Moreover, future studies would be helpful in further investigating the potential of an urban harvesting initiative to attenuate the financial burden of cancer treatment that may result in food insecurity.

Very few gardening interventions and no documented harvesting interventions have been conducted in cancer survivors and other high-risk patient populations. The 
results of this study suggest further research would be beneficial in understanding how to improve urban harvesting interventions for cancer survivors as well as other vulnerable populations. Additional qualitative and quantitative studies investigating dietary and physical improvements may provide further insights into this unique population.

Determining the positive outcomes, perceptions, and barriers associated with cancer survivors' harvesting fresh vegetables in a novel urban garden setting could inform future interventions aimed at improving overall adherence to the AICR's evidence-based guidelines for cancer survivorship. 


\title{
Chapter 5: Health Perceptions of Cancer Survivors Harvesting at an Urban Garden
}

\author{
Abstract \\ Due to advances in prevention, early detection, and treatment of cancer, the \\ proportion of cancer survivors increases dramatically each year. However, as a result of \\ the effects of cancer therapies, genetic predisposition, and lifestyle behaviors, cancer \\ survivors are at much greater risk for multiple comorbidities. Indeed, in healthy \\ populations, access to fresh produce in an urban garden-based setting has been effective \\ in improving dietary intakes, physical activity levels, and social support. Despite these \\ findings, no harvesting interventions specific to cancer survivors have been published. \\ Three focus groups of adult cancer survivors $(n=28)$ were conducted to determine if an \\ urban harvesting initiative improved perceptions of health and wellness in cancer \\ survivors. Four major overarching themes were identified from participant focus groups \\ including: (1) perceptions of improved mental and physical health, (2) adherence to a \\ plant-based diet and healthy modifications in cooking and meal planning, (3) greater \\ sense of community and social support, and (4) challenges to harvesting. These findings \\ provide preliminary results supporting positive outcomes associated with harvesting at an \\ urban garden setting for cancer survivors. These results will inform future interventions \\ aimed at improving overall adherence to evidence-based guidelines for cancer \\ survivorship.
}

Keywords: Nutrition, Gardening, Cancer Survivor, Qualitative Research, Focus Groups 


\section{Introduction}

As a result of advances in prevention, early detection, and treatment of cancer, there has been a steady decline in the cancer death rate over the last two decades. ${ }^{2}$ According to the American Cancer Society's (ACS) Cancer Treatment and Survivorship Facts and Figures, as of January 1, 2012, an estimated 13.7 million Americans were living with a history of cancer. ${ }^{1}$ As of January 1,2022 , this number is expected to increase to 18 million survivors. ${ }^{1}$ However, as a result of the effects of cancer treatment, genetic predisposition, and lifestyle behaviors, cancer survivors are at much greater risk for comorbidities including recurring primary cancers, secondary malignancies, cardiovascular disease, osteoporosis, diabetes, functional decline, and premature mortality and morbidity. ${ }^{1,5}$

Modifiable lifestyle behaviors have been shown to improve cancer outcomes for survivors..$^{4-6}$ The American Institute for Cancer Research/World Cancer Research Fund (AICR/WCRF) provides evidence-based guidelines for cancer prevention that include adopting a plant-based diet, engaging in regular physical activity, maintaining a healthy body weight, and other key lifestyle behavior recommendations. ${ }^{4}$ Research has documented that more than one-third of all cancers could be prevented by adhering to these guidelines. ${ }^{7}$ The ACS also promotes these behaviors to mitigate symptoms, reduce comorbidities, and improve overall health and functioning throughout survivorship.

JamesCare for Life (JCFL), an extension of Ohio State University's Comprehensive Cancer Center, provides a variety of resources and services to assist cancer patients and their families with navigating their cancer journey. The Garden of 
Hope $(\mathrm{GOH})$ is a complimentary cancer survivor garden that began in 2012 for JCFL cancer survivors. This two-acre urban garden provides access to harvests up to three times per week in two hour shifts during the growing season. During the 2013 harvest season, there were 170 unique GOH participants harvesting from June through August.

Though evidence on garden initiatives in adult cancer survivors remains limited, the literature reports that gardening interventions have been correlated with improvements in mental health, produce intake, socialization, physical functioning, perception of health-related well-being. ${ }^{12,14,41,42}$ Despite a growing body of evidence promoting gardening interventions in both youth ${ }^{12,18-23}$ and adults,,$^{14,16,17}$ very few studies focus on high-risk populations.

The GOH provides a novel setting for assessing perceptions of health and adherence to cancer survivorship guidelines. The purpose of this study was to determine the opinions of cancer survivors participating in an urban harvesting initiative. The perceptions and impact of receiving and utilizing the produce harvested during one growing season at the $\mathrm{GOH}$ was explored to inform future interventions aimed at improving overall adherence to the AICR's evidence-based guidelines for cancer survivorship. The results of this study provide insights into the health outcomes associated with harvesting produce in an urban garden setting for cancer survivors.

\section{Methods}

\section{Study Design and Recruitment}

Three focus groups $(n=28)$ consisting of adult cancer survivors were conducted in November 2013 in Columbus, Ohio. All participants provided written informed consent. 
Participants also completed a supplemental survey assessing demographics and basic cancer history. The survey was developed by a team of survey design experts and based largely upon the literature using a mix of new and validated questions. Food security status was assessed the USDA Economic Research Service's Six-Item Short Form of the Food Security Survey Model (FSSM). ${ }^{47}$

Participants were recruited via email distributed by the JCFL staff from an existing list of $170 \mathrm{GOH}$ participants. Individuals were eligible for the study if they were adults (>18) and participated in the $2013 \mathrm{GOH}$ harvest. Of the 170 participants who were emailed, 12 initially signed up for focus groups. JCFL then distributed a second email promoting the focus groups. Following that email, 18 more people signed up to participate. Two participants did not show up for the focus groups. The flow of recruitment of participants is illustrated in figure 5.1.

Each focus group lasted approximately two hours, consisted of seven to twelve participants per group, and was led by an experienced moderator. Focus groups were held at the same time and day of the week as the summer harvests to ensure availability of participants. A written guide was used during all focus groups, which included a series of open-ended questions and subsequent follow-up questions (Table 5.4). A graduate researcher was present at all focus groups to assist with data collection and transcription. Focus groups were audio-recorded using a digital device (2007-2009 Pulse Audio Smart Pens, Livescribe Inc., Oakland, CA) to minimize recorder bias. Individuals received a $\$ 10$ gift card for participating. The Human Subjects Institutional Review Board approved this study. 
Analysis

Audio recordings were transcribed verbatim by the graduate researcher in order to evaluate trends, observations, and common issues that developed throughout the discussions. The research team individually reviewed the data to determine recurring themes and subthemes. Inter-rater reliability was set at $85 \%$ and established by having two researchers analyze each transcript independently and compare for agreement in coding. After compared coding schemes, the research team achieved agreement on the thematic framework. This data was then imported into Ethnograph (version 6.0, Qualis Research Associates, Denver, CO), a computer program that codes items of interest and facilitates with the analysis and quantification of qualitative data. ${ }^{49}$ Secondary codes were then applied and sorted to facilitate analysis.

In order to improve the credibility and trustworthiness of the results, multiple verification strategies were used. The research team reflected on their personal and professional biases, including the concerns that both researchers were passionate about urban gardening and its impact on cancer survivorship. The research team acknowledged and accepted these biases, a process formally known as epoche. They then attempted to ensure that they saw the perspective of the participants and that the results were not exaggerated during the analysis based on these biases.

Triangulation of analysts and observers was also utilized to enhance credibility and trustworthiness. Both researchers were present during the focus groups and engaged in a debriefing session following each session in order to reflect upon the discussion. Furthermore, each researcher coded the transcripts independently, met to compare coding 
schemes and achieve consensus, and then coded subthemes separately again. The researchers maintained an audit trail documenting these processes.

Descriptive statistics were used to define the study population in terms of the subject characteristics: age, ethnicity, gender, relationship status, cancer history, age of diagnosis, number and type of cancers, treatment status, and comorbidities. Frequency analyses were conducted to determine the rate of self-reported health conditions (hypertension, type 2 diabetes mellitus, fibromyalgia, high cholesterol, anxiety, depression, irritable bowel syndrome, asthma, polycystic ovarian syndrome, and mitral valve prolapse) in this cohort. Surveys were coded and data was entered into Microsoft Excel (version 13.3.9). Responses to the FSSM were coded as affirmative or not affirmative according to the module's user notes. The sum of affirmative responses to the six questions in the survey is the household's raw score on the scale, which indicated the food security status on a scale of $0-6$, with low scores indicating high food security and high scores indicating lower food security. ${ }^{47}$

\section{Results}

A total of 28 survivors participated in the focus groups. Table 5.1 details the demographic characteristics and cancer history of participants. The majority of the participants were Caucasian (78.5\%), female (89.3\%) and not in active cancer treatment at the time of the study (78.6\%). The age range of all participants was $35-83$ years with a mean age of 62 . None of the participants were smokers. The most prevalent primary cancer was breast (53.5\%). One-fourth of the respondents reported a history of hypertension and $10 \%$ reported having diabetes. Participants harvested at the $\mathrm{GOH}$ an 
average of 12 times throughout the season. Half of the participants were categorized as food secure and $17.9 \%$ were marginally food secure. One-fourth of the participants were found to have low food security and $7 \%$ had very low food security (Table 5.3). Our sample was representative of the GOH participants for 2013 as well as representative of those that attended other JCFL programming, as illustrated in figure 5.1

Four major overarching themes were identified from participant focus groups including: (1) perceptions of improved mental and physical health, (2) adherence to a plant-based diet and healthy modifications in cooking and meal planning, (3) greater sense of community and social support, and (4) challenges to harvesting. Table 5.5 presents selected illustrative quotes of each theme. There were no major intergroup differences observed in the themes.

Improved Health

Many participants commented that the GOH improved their perception of mental and emotional health by providing an escape from the everyday stresses of living as a cancer survivor. The survivors described feeling psychologically better after consuming more produce and improving their dietary intakes. Moreover, the survivors shared that they felt a sense of responsibility and commitment to the GOH group that encouraged them to keep returning to harvest. While harvesting, several participants felt a strong spiritual connection to nature that brought back fond memories of family and childhood.

All of the survivors shared that they were very grateful for the opportunity to harvest at the $\mathrm{GOH}$ because post-treatment fatigue often prevented them from maintaining gardens at home. Many participants reported that harvesting at the $\mathrm{GOH}$ 
helped them to become more physically active. Many expressed that in addition to having an incentive to be more physically active outdoors, they felt a newfound sense of energy from the fresh produce that made them feel better, physically.

\section{Improved Nutrition}

Many participants shared that harvesting at the GOH helped to increase their produce intake and prepare vegetables in novel ways. When asked if they tried any new foods as a result of the garden, many replied that they indeed experimented with many new vegetables and recipes. Many participants mentioned that the bounty of produce allowed them to better adhere to a primarily plant-based diet and several noted a reduction in meat intake.

When asked how the produce harvested affected the participants' shopping, cooking, and eating habits, many shared that the garden made a significant difference in how they ate throughout the summer since they planned their meals around the produce harvested at the garden. Participants shared that they began investing more time in searching for new recipes and planning healthy meals in order to use all of the harvested produce and avoid waste. Several participants also commented on revisiting old cookbooks and cooking techniques such as canning, preserving and dehydrating. In addition to increasing plant consumption, participants shared that they often felt more compelled to snack on vegetables throughout the harvest season rather than default to traditional processed snack foods and desserts.

Support 
Respondents repeatedly expressed their appreciation for the sense of belonging, support and community that the GOH provided. Many participants said they enjoyed the social networking aspect of the garden, from meeting new survivors to conversing with acquaintances and students about shared experiences. Multiple participants described the garden as a meeting place where they could share ideas, give and gain support, and thrive in common conversation. When asked about interactions at the $\mathrm{GOH}$, many expressed appreciation for the dedication of the JCFL staff and volunteers, Waterman farm manager, and dietetic students. Several respondents shared that they particularly enjoyed the youth, enthusiasm, and knowledge of the dietetic students.

\section{Challenges}

Several cancer survivors commented that the harvesting windows were too narrow given conflicts with work, unpredictable traffic, and weather conditions. Some participants expressed a desire for longer or unlimited harvesting sessions. Survivors also shared that they would appreciate a greater variety of produce, harvesting tools, more educational materials, and recipes.

Another one of the challenges expressed by participants in all focus groups was maintaining these healthy habits acquired at the garden. Many participants reported having a hard time replicating on their own the produce intake they maintained during the harvest season because they were dissatisfied with the taste, textures, quality, and freshness of supermarket produce. Other participants emphasized suspicions related to preservatives and nutritional value of the supermarket 'fresh' produce since it rotted more quickly than the GOH produce. 


\section{Discussion}

To our knowledge, this is the first study that qualitatively explores the perceptions, outcomes, and challenges associated with cancer survivors harvesting fresh produce in an urban garden setting. These findings provide insights into the health perceptions associated with harvesting and its impact on cancer survivorship recommendations.

Consistent with the work of others, our results indicate that harvesting had a therapeutic effect on the participants ranging from reports of enhanced spirituality to increased socialization and improvements in well-being. ${ }^{13,50-53}$ Gardening has been correlated with stress relief and a sense of peace. ${ }^{53}$ Our results are consistent with these findings as survivors reported that the $\mathrm{GOH}$ distracted them from stressors related to cancer. Though previous studies have reported the benefits of a gardening on positive mental health and stress reduction, ${ }^{13,50,52,53}$ few are specific to cancer survivors and harvesting. $^{24}$

In addition to widespread stress reduction, the $\mathrm{GOH}$ also improved the participants' perceptions of mental health by providing a rich sense of community in which they felt they belonged. Studies have documented the connection between social support in a garden setting and improvement in perceptions of well-being. ${ }^{13,50}$ Additionally, survivors felt a strong sense of responsibility and commitment to this group. Participants also expressed appreciation for the community garden volunteers contributing to the garden's supportive environment. The healing process seemed to be enhanced by the strong social support networking at the GOH. This support was further 
magnified by participants that appeared to revisit fond childhood memories, often describing sentiments of close family ties connected to gardening.

Moreover, participants consistently reported perceptions of physical and mental connectedness with nature while harvesting. One participant described the garden as an urban "oasis" providing a sense of peaceful spirituality within the confines of a big city. The strength and conviction of the perceived therapeutic and spiritual effects of the GOH was striking; yet it has been previously documented. This reference to a connection linking soil and earth is consistent with previous studies documenting the restorative powers of nature. ${ }^{51,54,55}$ Frequent contact with nature has also been associated with reduced mortality and morbidity from stress-related diseases and faster recovery from acute and chronic stress. ${ }^{54}$ Heliker et al. reported improvements in psychological wellbeing and spiritual benefits that transcended cultural boundaries after a structured gardening intervention. ${ }^{50}$

Our results indicate that harvesting increased physical activity levels, which is consistent with previous studies documenting the physical benefits of gardening. ${ }^{17,24,34}$ Blair et al. documented that measures of physical function had the largest improvements in a mentored vegetable gardening intervention, surpassing produce intake and quality of life outcomes. ${ }^{24}$ Because cancer survivors are at an increased risk for comorbidities, physical activity plays a critical role in reducing risk in this vulnerable population. ${ }^{4,6,9,28,31,35}$ Regular physical activity is also associated with higher levels of physical functioning and physiological stability in older cancer survivors. ${ }^{14,34}$ Though our 
study did not evaluate physical function or fall risk, it has been documented that gardening in older adults has the potential for reducing fall risk and improving balance. ${ }^{17}$

The GOH harvesters consistently reported greater produce intake aligning with evidence-based dietary recommendations for cancer survivors to consume a primarily plant-based diet. Studies have documented the connection between improved access to fresh produce and increased fruit and vegetable intake in homebound low-income seniors, ${ }^{44,59}$ disadvantaged communities, ${ }^{60}$ and children, ${ }^{12,18-23}$ but few in cancer survivors. In addition to increased vegetable intake, McAleese and Rankin reported significant increases in vitamin $\mathrm{A}$, vitamin $\mathrm{C}$, and fiber intake following a garden-based nutrition education program in adolescents. ${ }^{22}$ It is evident that interventions combining gardening activities with a nutrition education component may enhance positive dietary outcomes. $^{12,18,19-23}$

Harvesting fresh produce was a cost-effective and enjoyable method of translating dietary guidelines into practice and may prove to be a novel intervention for many cancer survivors. In addition to attenuating the risk of comorbidities, consuming a primarily plant-based diet may also reduce obesity. ${ }^{57}$ In cancer survivors, obesity is highly correlated with cancer recurrence and reduced quality of life. ${ }^{37}$ One-fourth of the GOH harvesters reported a diagnosis of hypertension while $11 \%$ reported diabetes. For overweight cancer survivors, especially those suffering comorbidities, weight loss would be an effective and highly recommended strategy to attenuate obesity-related complications for survivors. ${ }^{10,35,37,38}$ 
Over the harvesting season, the GOH essentially became an outdoor support group where the cancer survivors could harvest, connect with one another, and share common health experiences. The importance of gardening as a venue for community engagement and networking has been well documented. ${ }^{16}$ Communicating and interacting with the volunteers and students who managed and maintained the garden seemed to enhance the social networking experience for the survivors.

The main barrier to harvesting at the GOH revolved around scheduling conflicts. The primary barrier to nutritional sustainability was related to widespread reports of disappointment with grocery store produce once the harvest season was over. It has been well documented that product quality, whether real or perceived, is a main driver of consumer interest in fruits and vegetables and can greatly impact a person's desire to eat fresh produce. ${ }^{61,62}$ Glanz et al. reported that taste preferences and nutrition are two of the greatest predictors of fruit and vegetable intake; however the discrepancy between produce from a grocery store versus a garden or farmer's market was not examined. ${ }^{62}$ It may be beneficial to educate survivors on the health benefits of canned or frozen produce in order to promote sustainability of a plant-based diet when fresh garden produce is unavailable. Providing additional recipes may also be helpful.

Though one-fourth of the participants were found to have low food security and $7 \%$ had very low food security, very few participants commented on whether having access to free produce at the $\mathrm{GOH}$ benefitted them financially. In addition, our question thread did not focus on perceptions related to food security. This line of inquiry could be interesting as many food insecure households report choosing between food and 
medicine/medical care ${ }^{67}$ Certainly, the GOH may provide the means for increasing produce intake for individuals who may have financial difficulties.

\section{Limitations}

The study had a relatively small sample size $(\mathrm{n}=28)$. A larger controlled trial would be beneficial in future studies evaluating the efficacy of and urban harvesting intervention. Bias may have been introduced by the inclusion of a GOH volunteer who was also present at the focus group discussions. However, we achieved saturation in themes after the first three focus groups which therefore did not necessitate additional focus group sessions. Furthermore, our sample was fairly representative of the 170 total participants that harvested during the season.

Though the average number of garden visits per season was twelve, a few participants reported only visiting the garden once or twice. This limited exposure to the harvests may have influenced responses. Additionally, some survivors had harvested with fewer time restrictions the previous year and therefore had differing views regarding barriers in scheduling. The study would have benefited from dividing those who harvested in previous year from new harvesters with no reference point in which to

compare. Lastly, although the student sat in the back to transcribe and observe, participants may have felt limited in what they could divulge and may have been guarded with their answers due to familiarity with the student. Further studies identifying the perceptions of cancer survivors harvesting at an urban garden are needed to either support or refute the findings of this study.

\section{Conclusions}


The results of this study provide preliminary support for positive perceptions of improved produce intake, mental and physical health, and community support for cancer survivors harvesting at an urban garden. The GOH provided access to fresh produce that may have not otherwise been purchased by the participants. The reported increase in produce consumption is promising as evidence-based scientific guidelines consistently recommended that cancer survivors adopt a primarily plant-based diet in order to prevent cancer reoccurrence and reduce the risk of future comorbidities. Very few gardening interventions and no documented harvesting interventions have been conducted in cancer survivors.

Recommendations for future studies include assessing the survivors' dietary intake, physical activity, physical function and measures of mental health at baseline in order to have a pre/post harvesting comparison. Using valid methods to quantify biomarkers of exposure to dietary intake in addition to obtaining objective measures of physical function and mental health might be useful in confirming self-report improvements in perceived health. It may also be helpful to provide more education on the guidelines for cancer survivorship and the importance of adhering to the recommendations.

Involving cancer survivors in the actual planting and gardening processes (versus strictly harvesting) may be beneficial in optimizing physical activity and enriching the overall harvesting experience. Participants expressed interested in giving back to the GOH by helping with the planting, garden maintenance, or volunteering at the check-in booth. The results of this study suggest further research may be beneficial in 
understanding how to improve urban harvesting interventions for cancer survivors as well as other vulnerable populations. Additional qualitative and quantitative studies investigating dietary and physical improvements may provide further insights into this vulnerable population. 


\begin{tabular}{lr}
\hline Variables & \\
\hline Age & $62.25(35-83)$ \\
Race & \\
Caucasian & $78.5 \%(\mathrm{n}=22)$ \\
African American & $10.7 \%(\mathrm{n}=3)$ \\
European-American & $3.6 \%(\mathrm{n}=1)$ \\
Polish-American & $3.6 \%(\mathrm{n}=1)$ \\
Latino & $3.6 \%(\mathrm{n}=1)$ \\
Gender & \\
Female & $89.3 \%(\mathrm{n}=25)$ \\
Male & $10.7 \%(\mathrm{n}=3)$ \\
Relationship Status & \\
Married & $53.6 \%(\mathrm{n}=15)$ \\
Widowed & $17.9 \%(\mathrm{n}=5)$ \\
Divorced & $10.7 \%(\mathrm{n}=3)$ \\
Living with partner & $10.7 \%(\mathrm{n}=3)$ \\
Single & $7.1 \%(\mathrm{n}=2)$ \\
Non-Smoker & $100 \%(\mathrm{n}=28)$ \\
Age of Cancer Diagnosis & $55.89(32-82)$ \\
Number of Cancers & $1.14(1-2)$ \\
Type of Cancer & \\
Breast & \\
Prostate & $53.5 \%(\mathrm{n}=15)$ \\
Lung & $7.1 \%(\mathrm{n}=2)$ \\
Ovarian & $7.1 \%(\mathrm{n}=2)$ \\
Colon & $3.6 \%(\mathrm{n}=1)$ \\
Mouth & $3.6 \%(\mathrm{n}=1)$ \\
Skin & $3.6 \%(\mathrm{n}=1)$ \\
Thyroid & $3.6 \%(\mathrm{n}=1)$ \\
Non-Hodgkin's & $3.6 \%(\mathrm{n}=1)$ \\
Lymphoma & $3.6 \%(\mathrm{n}=1)$ \\
No Response & \\
Treatment Status & $14.3 \%(\mathrm{n}=4)$ \\
Currently in Treatment & \\
Not in Treatment & $7.1 \%(\mathrm{n}=2)$ \\
No Response & $78.6 \%(\mathrm{n}=22)$ \\
\hline & $14.2 \%(\mathrm{n}=4)$ \\
\hline & \\
\hline &
\end{tabular}

Table 5.1 Subject Characteristics of Cancer Survivors Harvesting at an Urban Garden 
Table 5.1 (continued)

\begin{tabular}{lr}
\hline Other Diseases & \\
\hline Hypertension & $25.0 \%(\mathrm{n}=7)$ \\
Diabetes & $10.7 \%(\mathrm{n}=3)$ \\
Fibromyalgia & $3.6 \%(\mathrm{n}=1)$ \\
High cholesterol & $3.6 \%(\mathrm{n}=1)$ \\
Anxiety & $3.6 \%(\mathrm{n}=1)$ \\
Depression & $3.6 \%(\mathrm{n}=1)$ \\
IBS & $3.6 \%(\mathrm{n}=1)$ \\
Asthma & $3.5 \%(\mathrm{n}=1)$ \\
PCOS & $3.6 \%(\mathrm{n}=1)$ \\
Mitral valve prolapse & $3.6 \%(\mathrm{n}=1)$ \\
No Other Diseases & $25.0 \%(\mathrm{n}=7)$ \\
No Response & $36.0 \%(\mathrm{n}=10)$ \\
\hline
\end{tabular}

\begin{tabular}{cccc}
\hline & $\begin{array}{c}\text { 2013 JCFL } \\
\text { Survey of } \\
\text { Participants } \\
(\mathbf{n}=87)\end{array}$ & $\begin{array}{c}\text { 2013 JCFL Survey } \\
\text { of GOH } \\
\text { Participants } \\
(\mathbf{n}=60)\end{array}$ & $\begin{array}{c}\text { 2013 GOH } \\
\text { Participants } \\
(\mathbf{n}=\mathbf{2 8})\end{array}$ \\
\hline Age Range & $50-79$ & N/A & $35-83$ \\
\hline Gender & & & \\
\hline Female & $81 \%(\mathrm{n}=70)$ & N/A & $\begin{array}{c}89.3 \% \\
(\mathrm{n}=25)\end{array}$ \\
\hline Male & $19 \%(\mathrm{n}=17)$ & N/A & $10.7 \%(\mathrm{n}=3)$ \\
\hline Ethnicity & & & $78.5 \%$ \\
\hline Caucasian & $90 \%(\mathrm{n}=78)$ & $86.7 \%(\mathrm{n}=52)$ & $10.7 \%(\mathrm{n}=3)$ \\
\hline African & $8 \%(\mathrm{n}=7)$ & $5 \%(\mathrm{n}=3)$ & \\
\hline American & & & $53.5 \%$ \\
\hline Type of Cancer & & $47 \%(\mathrm{n}=28)$ & $7.1 \%(\mathrm{n}=2)$ \\
\hline Breast & $54.8 \%(\mathrm{n}=47)$ & &
\end{tabular}

Table 5.2 Representativeness of Garden of Hope Participants 


\begin{tabular}{ll}
\hline Food Security Status & \\
\hline High food security & $50.0 \%(\mathrm{n}=14)$ \\
Marginal food security & $17.9 \%(\mathrm{n}=5)$ \\
Low food security & $25.0 \%(\mathrm{n}=7)$ \\
Very low food security & $7.1 \%(\mathrm{n}=2)$ \\
\hline
\end{tabular}

Table 5.3 Food Security Status of Cancer Survivors Harvesting at an Urban Garden 
1. Tell me your thoughts about the Garden of Hope program.

- Do you believe the Garden of Hope was a positive experience?

- What barriers or challenges did you encounter throughout the program?

2. Did the Garden of Hope program impact your health in any way?

- Did you make any changes to your diet throughout the program?

- Did the program affect your level of physical activity?

3. Did you interact with anyone throughout the Garden of Hope program? Tell me about that experience.

- JamesCare staff

- Student dietetic interns

- Other survivors

4. Tell me how you used the foods you harvested at the Garden of Hope.

- Did the produce harvested affect your shopping, cooking and eating habits?

- Were there any foods you harvested that you didn't know how to prepare or cook at home?

- Did you try any new foods as a result of the Garden of Hope program?

- Are these foods you will continue to eat?

5. How would you improve the Garden of Hope program?

6. Do you have any additional comments or concerns?

Table 5.4 Focus Group Open-Ended Discussion Question Thread 


\begin{tabular}{|c|c|}
\hline Themes & Participant Quotes Supporting Themes \\
\hline \multicolumn{2}{|l|}{ Improved Health } \\
\hline \multirow[t]{2}{*}{ Mental Health } & $\begin{array}{l}\text { Not only mentally but physically, it really brought not only } \\
\text { peace for her but also for the stress as a caretaker. Just } \\
\text { getting out there and picking, and even helping others } \\
\text { pick, getting your hands dirty, really mentally helps some } \\
\text { of that stress get into the land and not in your heart and } \\
\text { your body. I just felt really good being there, it was fun to } \\
\text { pick things. }\end{array}$ \\
\hline & $\begin{array}{l}\text {...you're standing here, you know you're in the middle of } \\
\text { this big city, but you're on this oasis, ya know, and you } \\
\text { can just block everything out. And it was, it was very } \\
\text { spiritual. }\end{array}$ \\
\hline \multirow[t]{2}{*}{ Physical Health } & $\begin{array}{l}\text { I did feel physically different. I felt lighter; and I felt like I } \\
\text { could skip. }\end{array}$ \\
\hline & $\begin{array}{l}\text { I got out because this is mine. I got out and I was walking } \\
\text { along, otherwise I could have been home laying on the } \\
\text { couch or sitting on the couch but I was actually walking } \\
\text { around the garden and picking. It kind of pushed me } \\
\text { outside. }\end{array}$ \\
\hline \multicolumn{2}{|l|}{ Improved Nutrition } \\
\hline \multirow[t]{2}{*}{$\begin{array}{l}\text { Adherence to a Plant- } \\
\text { Based Diet }\end{array}$} & $\begin{array}{l}\text { It benefitted me because I learned to actually make more } \\
\text { vegetable dishes than I usually do. Most of the time we } \\
\text { were eating vegetable dishes instead of meats, which } \\
\text { helped. }\end{array}$ \\
\hline & $\begin{array}{l}\text { It helped us increase the number of vegetables we eat, } \\
\text { even to the point where as we plan our Thanksgiving } \\
\text { holiday meal, it will be more vegetarian than it has been } \\
\text { before. }\end{array}$ \\
\hline \multirow{2}{*}{$\begin{array}{l}\text { Healthy Modifications } \\
\text { in Cooking and Meal } \\
\text { Planning }\end{array}$} & $\begin{array}{l}\text { It became the focus of my diet. It was the core around } \\
\text { which I structured my other protein and foods. }\end{array}$ \\
\hline & $\begin{array}{l}\text { Just getting produce forced me to invest a little more time } \\
\text { in meal planning and what it is I was making...having all } \\
\text { this produce, I'm suddenly looking for recipes for different } \\
\text { dishes to make or different breads to bake. So it forced me } \\
\text { to take a closer look at what we we're eating and how we } \\
\text { were preparing food... }\end{array}$ \\
\hline
\end{tabular}

Table 5.5. Overarching Themes from Participant Focus Groups 
Table 5.5 (continued)

\begin{tabular}{|c|c|}
\hline \multirow[t]{2}{*}{$\begin{array}{l}\text { Greater Sense of } \\
\text { Community and Social } \\
\text { Support }\end{array}$} & $\begin{array}{l}\text { Going to the garden you were part of a bigger circle of } \\
\text { people....I think there's a lot of compassion in doing } \\
\text { gardening with others that share something in common. }\end{array}$ \\
\hline & $\begin{array}{l}\text {...it was really beneficial, I thought, to have students be } \\
\text { part of this activity...They were young and vital and } \\
\text { they knew stuff; and they plunged right in and became } \\
\text { part of the community. }\end{array}$ \\
\hline \multicolumn{2}{|l|}{ Challenges } \\
\hline Scheduling & $\begin{array}{l}\text { It would be better if we had more set days, more time, } \\
\text { being as large it is. And all of us work and stuff and we } \\
\text { have to rush to get here or there. }\end{array}$ \\
\hline Adherence & $\begin{array}{l}\text { Now that it's autumn and I'm using stuff from the store, } \\
\text { I'm not happy with what I'm making. The choices are } \\
\text { slimmer in terms of how long the food's gonna last. It } \\
\text { was lovely to get a cucumber and know that it would } \\
\text { last for a couple of weeks. }\end{array}$ \\
\hline
\end{tabular}




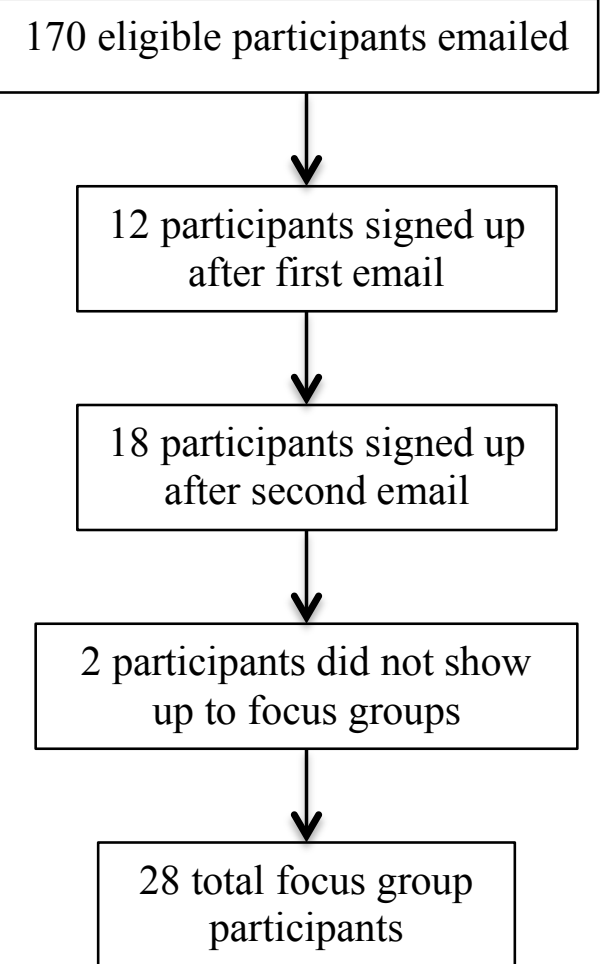

Figure 5.1 Recruitment and Flow of Participants Through Study 


\section{References}

1. American Cancer Society. Cancer Treatment \& Survivorship Facts \& Figures 2014. Atlanta: American Cancer Society; 2014.

2. Siegel R, Ma J, Zou Z, Jemal A. Cancer statistics, 2014. CA Cancer J Clin. 2014;64(1):9-29. doi:10.3322/caac.21208.

3. Demark-Wahnefried W, Jones LW. Promoting a healthy lifestyle among cancer survivors. Hematol Oncol Clin North Am. 2008;22(2):319-342, viii. doi:10.1016/j.hoc.2008.01.012.

4. World Cancer Research Fund, American Institute for Cancer Research. Food, nutrition, physical activity, and the prevention of cancer: a global perspective. Washington, DC: WCRF/AICR; 2007.

5. Winzer BM, Whiteman DC, Reeves MM, Paratz JD. Physical activity and cancer prevention: a systematic review of clinical trials. Cancer Causes Control CCC. 2011;22(6):811-826. doi:10.1007/s10552-011-9761-4.

6. Danaei G, Vander Hoorn S, Lopez AD, Murray CJL, Ezzati M. Causes of cancer in the world: comparative risk assessment of nine behavioural and environmental risk factors. Lancet. 2005;366(9499):1784-1793. doi:10.1016/S0140-6736(05)67725-2.

7. Wang MC, Rauzon S, Studer N, et al. Exposure to a comprehensive school intervention increases vegetable consumption. J Adolesc Heal Off Publ Soc Adolesc Med. 2010;47(1):74-82. doi:10.1016/j.jadohealth.2009.12.014.

8. Brown VM, Allen AC, Dwozan M, Mercer I, Warren K. Indoor gardening older adults: effects on socialization, activities of daily living, and loneliness. J Gerontol Nurs. 2004;30(10):34-42.

9. Bashirian S, Allahverdipour H, Moeini B. Fruit and Vegetable Intakes among Elementary Schools' Pupils: Using Five-A-Day Educational Program. J Res Heal Sci. 2008;8(1):56-63.

10. Davis EM, Cullen KW, Watson KB, Konarik M, Radcliffe J. A Fresh Fruit and Vegetable Program improves high school students' consumption of fresh produce. $J$ Am Diet Assoc. 2009;109(7):1227-1231. doi:10.1016/j.jada.2009.04.017.

11. Gatto NM, Ventura EE, Cook LT, Gyllenhammer LE, Davis JN. LA Sprouts: a garden-based nutrition intervention pilot program influences motivation and preferences for fruits and vegetables in Latino youth. $J$ Acad Nutr Diet. 2012;112(6):913-920. doi:10.1016/j.jand.2012.01.014. 
12. McAleese JD, Rankin LL. Garden-based nutrition education affects fruit and vegetable consumption in sixth-grade adolescents. J Am Diet Assoc. 2007;107(4):662-665. doi:10.1016/j.jada.2007.01.015.

13. Heim S, Stang J, Ireland M. A garden pilot project enhances fruit and vegetable consumption among children. J Am Diet Assoc. 2009;109(7):1220-1226. doi:10.1016/j.jada.2009.04.009.

14. Parmer SM, Salisbury-Glennon J, Shannon D, Struempler B. School gardens: an experiential learning approach for a nutrition education program to increase fruit and vegetable knowledge, preference, and consumption among second-grade students. J Nutr Educ Behav. 2009;41(3):212-217. doi:10.1016/j.jneb.2008.06.002.

15. Lombard KA, Beresford SAA, Ornelas IJ, et al. Healthy Gardens/Healthy Lives: Navajo Perceptions of Growing Food Locally to Prevent Diabetes and Cancer. Health Promot Pract. 2013. doi:10.1177/1524839913492328.

16. Chen T-Y, Janke MC. Gardening as a potential activity to reduce falls in older adults. J Aging Phys Act. 2012;20(1):15-31.

17. Wakefield S, Yeudall F, Taron C, Reynolds J, Skinner A. Growing urban health: Community gardening in South-East Toronto. Heal Promot Int. 2007;22(2):92-101. doi:10.1093/heapro/dam001.

18. Armstrong D. A survey of community gardens in upstate New York: implications for health promotion and community development. Health Place. 2000;6(4):319327.

19. Blair CK, Madan-Swain A, Locher JL, et al. Harvest for Health Gardening Intervention Feasibility Study in Cancer Survivors. Acta Oncol Stockh Swed. 2013;52(6):1110-1118. doi:10.3109/0284186X.2013.770165.

20. U.S. Household Food Security Survey Module: Six-Item Short Form. USDA; 2012. Available at:

http://www.ers.usda.gov/datafiles/Food_Security_in_the_United_States/Food_Secur ity_Survey_Modules/short2012.pdf.

21. JITE v33n4 - Under Review - The Ethnograph. Available at: http://scholar.lib.vt.edu/ejournals/JITE/v33n4/jite-v33n4.satchwell.html. Accessed February 2, 2014.

22. Heliker D, Chadwick A, O'Connell T. The Meaning of Gardening and the Effects on Perceived Well Being of a Gardening Project on Diverse Populations of Elders. Act Adapt Aging. 2001;24(3):35-56. doi:10.1300/J016v24n03_03. 
23. Tse M. Therapeutic effects of an indoor gardening programme for older people living in nursing homes. J Clin Nurs. 2010;19(7-8):949-958. doi:10.1111/j.13652702.2009.02803.x.

24. Unruh A, Hutchinson S. Embedded spirituality: gardening in daily life and stressful life experiences. Scand J Caring Sci. 2011;25(3):567-574. doi:10.1111/j.14716712.2010.00865.x.

25. Detweiler MB, Sharma T, Detweiler JG, et al. What Is the Evidence to Support the Use of Therapeutic Gardens for the Elderly? Psychiatry Investig. 2012;9(2):100110. doi:10.4306/pi.2012.9.2.100.

26. Van Den Berg AE, Custers MHG. Gardening promotes neuroendocrine and affective restoration from stress. $J$ Heal Psychol. 2011;16(1):3-11. doi: $10.1177 / 1359105310365577$.

27. Hartig T, Evans GW, Jamner LD, Davis DS, Gärling T. Tracking restoration in natural and urban field settings. J Environ Psychol. 2003;23(2):109-123. doi:10.1016/S0272-4944(02)00109-3.

28. Van den Berg AE, Hartig T, Staats H. Preference for Nature in Urbanized Societies: Stress, Restoration, and the Pursuit of Sustainability. J Soc Issues. 2007;63(1):7996. doi:10.1111/j.1540-4560.2007.00497.x.

29. Demark-Wahnefried W, Clipp EC, Morey MC, et al. Physical function and associations with diet and exercise: Results of a cross-sectional survey among elders with breast or prostate cancer. Int J Behav Nutr Phys Act. 2004;1(1):16. doi:10.1186/1479-5868-1-16.

30. Rock CL, Doyle C, Demark-Wahnefried W, et al. Nutrition and physical activity guidelines for cancer survivors. CA Cancer J Clin. 2012;(62):242-274.

31. Vergnaud A-C, Romaguera D, Peeters PH, et al. Adherence to the World Cancer Research Fund/American Institute for Cancer Research guidelines and risk of death in Europe: results from the European Prospective Investigation into Nutrition and Cancer cohort study. Am J Clin Nutr. 2013;97(5):1107-1120. doi:10.3945/ajen.112.049569.

32. Blanchard CM, Courneya KS, Stein K. Cancer Survivors' Adherence to Lifestyle Behavior Recommendations and Associations With Health-Related Quality of Life: Results From the American Cancer Society's SCS-II. J Clin Oncol. 2008;26(13):2198-2204. doi:10.1200/JCO.2007.14.6217. 
33. Johnson DB, Beaudoin S, Smith LT, Beresford SAA, LoGerfo JP. Increasing fruit and vegetable intake in homebound elders: the Seattle Senior Farmers' Market Nutrition Pilot Program. Prev Chronic Dis. 2004;1(1):A03.

34. Abusabha R, Namjoshi D, Klein A. Increasing access and affordability of produce improves perceived consumption of vegetables in low-income seniors. $J$ Am Diet Assoc. 2011;111(10):1549-1555. doi:10.1016/j.jada.2011.07.003.

35. Jennings A, Cassidy A, Winters T, et al. Positive effect of a targeted intervention to improve access and availability of fruit and vegetables in an area of deprivation. Health Place. 2012;18(5):1074-1078. doi:10.1016/j.healthplace.2012.05.001.

36. Tuso PJ, Ismail MH, Ha BP, Bartolotto C. Nutritional Update for Physicians: PlantBased Diets. Perm J. 2013;17(2):61-66. doi:10.7812/TPP/12-085.

37. Rock CL, Demark-Wahnefried W. Nutrition and Survival After the Diagnosis of Breast Cancer: A Review of the Evidence. J Clin Oncol Off J Am Soc Clin Oncol. 2002;20(15):3302-3316. doi:10.1200/JCO.2002.03.008.

38. Demark-Wahnefried W, Aziz NM, Rowland JH, Pinto BM. Riding the Crest of the Teachable Moment: Promoting Long-Term Health After the Diagnosis of Cancer. $J$ Clin Oncol Off J Am Soc Clin Oncol. 2005;23(24):5814-5830. doi:10.1200/JCO.2005.01.230.

39. Argilés JM, López-Soriano FJ. Insulin and cancer (Review). Int J Oncol. 2001;18(4):683-687.

40. Scheerens JC. Phytochemicals and the Consumer: Factors Affecting Fruit and Vegetable Consumption and the Potential for Increasing Small Fruit in the Diet. HortTechnology. 2001;11(4):547-556.

41. GLANZ K, BASIL M, MAIBACH E, GOLDBERG J, SNYDER D. Why Americans Eat What They Do: Taste, Nutrition, Cost, Convenience, and Weight Control Concerns as Influences on Food Consumption. J Am Diet Assoc. 1998;98(10):1118-1126. doi:10.1016/S0002-8223(98)00260-0. 


\section{References}

1. American Cancer Society. Cancer Treatment \& Survivorship Facts \& Figures 2014. Atlanta: American Cancer Society; 2014.

2. Siegel R, Ma J, Zou Z, Jemal A. Cancer statistics, 2014. CA Cancer J Clin. 2014;64(1):9-29. doi:10.3322/caac.21208.

3. Aziz NM. Cancer Survivorship Research: Challenge and Opportunity. J Nutr. 2002;132(11):3494S-3503S.

4. World Cancer Research Fund, American Institute for Cancer Research. Food, nutrition, physical activity, and the prevention of cancer: a global perspective. Washington, DC: WCRF/AICR; 2007.

5. Demark-Wahnefried W, Jones LW. Promoting a healthy lifestyle among cancer survivors. Hematol Oncol Clin North Am. 2008;22(2):319-342, viii. doi:10.1016/j.hoc.2008.01.012.

6. Winzer BM, Whiteman DC, Reeves MM, Paratz JD. Physical activity and cancer prevention: a systematic review of clinical trials. Cancer Causes Control CCC. 2011;22(6):811-826. doi:10.1007/s10552-011-9761-4.

7. Danaei G, Vander Hoorn S, Lopez AD, Murray CJL, Ezzati M. Causes of cancer in the world: comparative risk assessment of nine behavioural and environmental risk factors. Lancet. 2005;366(9499):1784-1793. doi:10.1016/S0140-6736(05)67725-2.

8. Bellizzi KM, Rowland JH, Jeffery DD, McNeel T. Health behaviors of cancer survivors: examining opportunities for cancer control intervention. J Clin Oncol Off J Am Soc Clin Oncol. 2005;23(34):8884-8893. doi:10.1200/JCO.2005.02.2343.

9. Blanchard CM, Courneya KS, Stein K. Cancer Survivors' Adherence to Lifestyle Behavior Recommendations and Associations With Health-Related Quality of Life: Results From the American Cancer Society's SCS-II. J Clin Oncol. 2008;26(13):2198-2204. doi:10.1200/JCO.2007.14.6217.

10. Demark-Wahnefried W, Aziz NM, Rowland JH, Pinto BM. Riding the Crest of the Teachable Moment: Promoting Long-Term Health After the Diagnosis of Cancer. $J$ Clin Oncol Off J Am Soc Clin Oncol. 2005;23(24):5814-5830. doi:10.1200/JCO.2005.01.230. 
11. Blanchard CM, Stein KD, Baker F, et al. Association between current lifestyle behaviors and health-related quality of life in breast, colorectal, and prostate cancer survivors. Psychol Heal. 2004;19(1):1-13. doi:10.1080/08870440310001606507.

12. Wang MC, Rauzon S, Studer N, et al. Exposure to a comprehensive school intervention increases vegetable consumption. J Adolesc Heal Off Publ Soc Adolesc Med. 2010;47(1):74-82. doi:10.1016/j.jadohealth.2009.12.014.

13. Tse M. Therapeutic effects of an indoor gardening programme for older people living in nursing homes. J Clin Nurs. 2010;19(7-8):949-958. doi:10.1111/j.13652702.2009.02803.x.

14. Brown VM, Allen AC, Dwozan M, Mercer I, Warren K. Indoor gardening older adults: effects on socialization, activities of daily living, and loneliness. J Gerontol Nurs. 2004;30(10):34-42.

15. Blanchard CM, Cokkinides V, Courneya KS, Nehl EJ, Stein K, Baker F. A comparison of physical activity of posttreatment breast cancer survivors and noncancer controls. Behav Med Wash DC. 2003;28(4):140-149. doi:10.1080/08964280309596052.

16. Lombard KA, Beresford SAA, Ornelas IJ, et al. Healthy Gardens/Healthy Lives: Navajo Perceptions of Growing Food Locally to Prevent Diabetes and Cancer. Health Promot Pract. 2013. doi:10.1177/1524839913492328.

17. Chen T-Y, Janke MC. Gardening as a potential activity to reduce falls in older adults. J Aging Phys Act. 2012;20(1):15-31.

18. Parmer SM, Salisbury-Glennon J, Shannon D, Struempler B. School gardens: an experiential learning approach for a nutrition education program to increase fruit and vegetable knowledge, preference, and consumption among second-grade students. J Nutr Educ Behav. 2009;41(3):212-217. doi:10.1016/j.jneb.2008.06.002.

19. Bashirian S, Allahverdipour H, Moeini B. Fruit and Vegetable Intakes among Elementary Schools' Pupils: Using Five-A-Day Educational Program. J Res Heal Sci. 2008;8(1):56-63.

20. Davis EM, Cullen KW, Watson KB, Konarik M, Radcliffe J. A Fresh Fruit and Vegetable Program improves high school students' consumption of fresh produce. $J$ Am Diet Assoc. 2009;109(7):1227-1231. doi:10.1016/j.jada.2009.04.017.

21. Gatto NM, Ventura EE, Cook LT, Gyllenhammer LE, Davis JN. LA Sprouts: a garden-based nutrition intervention pilot program influences motivation and preferences for fruits and vegetables in Latino youth. J Acad Nutr Diet. 2012;112(6):913-920. doi:10.1016/j.jand.2012.01.014. 
22. McAleese JD, Rankin LL. Garden-based nutrition education affects fruit and vegetable consumption in sixth-grade adolescents. J Am Diet Assoc. 2007;107(4):662-665. doi:10.1016/j.jada.2007.01.015.

23. Heim S, Stang J, Ireland M. A garden pilot project enhances fruit and vegetable consumption among children. J Am Diet Assoc. 2009;109(7):1220-1226. doi:10.1016/j.jada.2009.04.009.

24. Blair CK, Madan-Swain A, Locher JL, et al. Harvest for Health Gardening Intervention Feasibility Study in Cancer Survivors. Acta Oncol Stockh Swed. 2013;52(6):1110-1118. doi:10.3109/0284186X.2013.770165.

25. JamesCare for Life 2013 Participant Survey Results Summary. The James Comprehensive Cancer center: The Ohio State University Wexner Medical Center; 2013.

26. Schmitz KH, Courneya KS, Matthews C, et al. American College of Sports Medicine roundtable on exercise guidelines for cancer survivors. Med Sci Sports Exerc. 2010;42(7):1409-1426. doi:10.1249/MSS.0b013e3181e0c112.

27. Vergnaud A-C, Romaguera D, Peeters PH, et al. Adherence to the World Cancer Research Fund/American Institute for Cancer Research guidelines and risk of death in Europe: results from the European Prospective Investigation into Nutrition and Cancer cohort study. Am J Clin Nutr. 2013;97(5):1107-1120. doi:10.3945/ajen.112.049569.

28. Hastert TA, Beresford SAA, Patterson RE, Kristal AR, White E. Adherence to WCRF/AICR Cancer Prevention Recommendations and Risk of Postmenopausal Breast Cancer. Cancer Epidemiol Biomarkers Prev. 2013. doi:10.1158/10559965.EPI-13-0210.

29. White E, Patterson RE, Kristal AR, et al. VITamins And Lifestyle Cohort Study: Study Design and Characteristics of Supplement Users. Am J Epidemiol. 2004;159(1):83-93. doi:10.1093/aje/kwh010.

30. Pekmezi DW, Demark-Wahnefried W. Updated Evidence in Support of Diet and Exercise Interventions in Cancer Survivors. Acta Oncol Stockh Swed. 2011;50(2):167-178. doi:10.3109/0284186X.2010.529822.

31. Pierce JP, Stefanick ML, Flatt SW, et al. Greater Survival After Breast Cancer in Physically Active Women With High Vegetable-Fruit Intake Regardless of Obesity. J Clin Oncol. 2007;25(17):2345-2351 . doi:10.1200/JCO.2006.08.6819.

32. Bloom JR, Stewart SL, D'Onofrio CN, Luce J, Banks PJ. Addressing the needs of young breast cancer survivors at the 5 year milestone: can a short-term, low 
intensity intervention produce change? J Cancer Surviv Res Pr. 2008;2(3):190-204. doi:10.1007/s11764-008-0058-x.

33. Campbell MK, Carr C, DeVellis B, et al. A Randomized Trial of Tailoring and Motivational Interviewing to Promote Fruit and Vegetable Consumption for Cancer Prevention and Control. Ann Behav Med. 2009;38(2):71-85. doi:10.1007/s12160009-9140-5.

34. Demark-Wahnefried W, Clipp EC, Morey MC, et al. Physical function and associations with diet and exercise: Results of a cross-sectional survey among elders with breast or prostate cancer. Int J Behav Nutr Phys Act. 2004;1(1):16. doi:10.1186/1479-5868-1-16.

35. Rock CL, Doyle C, Demark-Wahnefried W, et al. Nutrition and physical activity guidelines for cancer survivors. CA Cancer J Clin. 2012;(62):242-274.

36. Full Text PDF. Available at: http://www.ijbnpa.org/content/pdf/1479-5868-116.pdf. Accessed July 18, 2013.

37. Rock CL, Demark-Wahnefried W. Nutrition and Survival After the Diagnosis of Breast Cancer: A Review of the Evidence. J Clin Oncol Off J Am Soc Clin Oncol. 2002;20(15):3302-3316. doi:10.1200/JCO.2002.03.008.

38. Argilés JM, López-Soriano FJ. Insulin and cancer (Review). Int J Oncol. 2001;18(4):683-687.

39. Brown BW, Brauner C, Minnotte MC. Noncancer deaths in white adult cancer patients. J Natl Cancer Inst. 1993;85(12):979-987.

40. Suta Emina. Barriers to providing nutrition counseling by primary care physicians: opportunities for registered dietitans. Ohio State Univ. 2012.

41. Wakefield S, Yeudall F, Taron C, Reynolds J, Skinner A. Growing urban health: Community gardening in South-East Toronto. Heal Promot Int. 2007;22(2):92-101. doi:10.1093/heapro/dam001.

42. Armstrong D. A survey of community gardens in upstate New York: implications for health promotion and community development. Health Place. 2000;6(4):319327.

43. Twiss J, Dickinson J, Duma S, Kleinman T, Paulsen H, Rilveria L. Community gardens: lessons learned from California Healthy Cities and Communities. Am J Public Health. 2003;93(9):1435-1438. 
44. Johnson DB, Beaudoin S, Smith LT, Beresford SAA, LoGerfo JP. Increasing fruit and vegetable intake in homebound elders: the Seattle Senior Farmers' Market Nutrition Pilot Program. Prev Chronic Dis. 2004;1(1):A03.

45. Mary Debus. Handbook for Excellence in Focus Group Research. Washington, DC: The Academy for Educational Development; :1-55.

46. Krueger RA, Casey MA. Focus groups: a practical guide for applied research. Los Angeles: SAGE; 2009.

47. U.S. Household Food Security Survey Module: Six-Item Short Form. USDA; 2012. Available at:

http://www.ers.usda.gov/datafiles/Food_Security_in_the_United_States/Food_Secur ity_Survey_Modules/short2012.pdf.

48. USDA Economic Research Service - Survey Tools. Available at: http://www.ers.usda.gov/topics/food-nutrition-assistance/food-security-in-theus/survey-tools.aspx\#.Uu7DC2RDuMV. Accessed February 2, 2014.

49. JITE v33n4 - Under Review - The Ethnograph. Available at: http://scholar.lib.vt.edu/ejournals/JITE/v33n4/jite-v33n4.satchwell.html. Accessed February 2, 2014.

50. Heliker D, Chadwick A, O'Connell T. The Meaning of Gardening and the Effects on Perceived Well Being of a Gardening Project on Diverse Populations of Elders. Act Adapt Aging. 2001;24(3):35-56. doi:10.1300/J016v24n03_03.

51. Unruh A, Hutchinson S. Embedded spirituality: gardening in daily life and stressful life experiences. Scand J Caring Sci. 2011;25(3):567-574. doi:10.1111/j.14716712.2010.00865.x.

52. Detweiler MB, Sharma T, Detweiler JG, et al. What Is the Evidence to Support the Use of Therapeutic Gardens for the Elderly? Psychiatry Investig. 2012;9(2):100110. doi:10.4306/pi.2012.9.2.100.

53. Van Den Berg AE, Custers MHG. Gardening promotes neuroendocrine and affective restoration from stress. J Heal Psychol. 2011;16(1):3-11. doi: $10.1177 / 1359105310365577$.

54. Van den Berg AE, Hartig T, Staats H. Preference for Nature in Urbanized Societies: Stress, Restoration, and the Pursuit of Sustainability. J Soc Issues. 2007;63(1):7996. doi:10.1111/j.1540-4560.2007.00497.x. 
55. Hartig T, Evans GW, Jamner LD, Davis DS, Gärling T. Tracking restoration in natural and urban field settings. J Environ Psychol. 2003;23(2):109-123. doi:10.1016/S0272-4944(02)00109-3.

56. Nakau M, Imanishi J, Imanishi J, et al. Spiritual care of cancer patients by integrated medicine in urban green space: a pilot study. Explore New York N. 2013;9(2):87-90. doi:10.1016/j.explore.2012.12.002.

57. Tuso PJ, Ismail MH, Ha BP, Bartolotto C. Nutritional Update for Physicians: PlantBased Diets. Perm J. 2013;17(2):61-66. doi:10.7812/TPP/12-085.

58. Lanou AJ, Svenson B. Reduced cancer risk in vegetarians: an analysis of recent reports. Cancer Manag Res. 2010;3:1-8. doi:10.2147/CMR.S6910.

59. Abusabha R, Namjoshi D, Klein A. Increasing access and affordability of produce improves perceived consumption of vegetables in low-income seniors. J Am Diet Assoc. 2011;111(10):1549-1555. doi:10.1016/j.jada.2011.07.003.

60. Jennings A, Cassidy A, Winters T, et al. Positive effect of a targeted intervention to improve access and availability of fruit and vegetables in an area of deprivation. Health Place. 2012;18(5):1074-1078. doi:10.1016/j.healthplace.2012.05.001.

61. Scheerens JC. Phytochemicals and the Consumer: Factors Affecting Fruit and Vegetable Consumption and the Potential for Increasing Small Fruit in the Diet. HortTechnology. 2001;11(4):547-556.

62. GLANZ K, BASIL M, MAIBACH E, GOLDBERG J, SNYDER D. Why Americans Eat What They Do: Taste, Nutrition, Cost, Convenience, and Weight Control Concerns as Influences on Food Consumption. J Am Diet Assoc. 1998;98(10):1118-1126. doi:10.1016/S0002-8223(98)00260-0.

63. Eyre HJ, Feldman GE. Status report on prostate cancer in African Americans: a national blueprint for action. CA Cancer J Clin. 1998;48(5):315-319.

64. Kagawa-Singer M. Socioeconomic and cultural influences on cancer care of women. Semin Oncol Nurs. 1995;11(2):109-119.

65. Lyman GH, Kuderer NM, Lyman SL, Cox CE, Reintgen D, Baekey P. Importance of race on breast cancer survival. Ann Surg Oncol. 1997;4(1):80-87.

66. Cancer Prevalence and Cost of Care Projections. National Cancer Institute Available at: http://costprojections.cancer.gov/. Accessed March 13, 2014.

67. Mabli J, Cohen R, Potter F, et al. Hunger in America 2010: National Report Prepared for Feeding America. Chicago, IL; 2010. 
68. Anderson JV, Bybee DI, Brown RM, et al. 5 a day fruit and vegetable intervention improves consumption in a low income population. J Am Diet Assoc.

2001;101(2):195-202. doi:10.1016/S0002-8223(01)00052-9. 
Appendix A: Letter to Participant 


\section{Dear Participant:}

I'm writing to let you know that as a participant of the Garden of Hope (GOH) program, you have the option to participate in focus groups to discuss the benefits, barriers, challenges and overall health perceptions of harvesting at the GOH. If you choose NOT to participate in the focus groups, it will not affect your participation in the program. If you are interested, please let me know and then you will be contacted about the dates/times of the focus groups. Focus group sessions will last approximately 90 minutes to two hours. If you choose to participate in the focus groups, then you will be asked to sign a consent form prior to beginning the focus group discussion. The consent form is included with this letter. Please read the document over and contact Alexis Joseph if you have any questions. You will receive a \$10 gift card for attending the focus group session. Please contact Alexis if you have any questions, concerns and/or would like to enroll and/or know more about the focus groups. See below for Alexis' contact information.

Sincerely,

Vicki Brown

Program Coordinator

JamesCare for Life

P: (614)293-0825

F: (614)293-9622

http:/www.cancer.osu.edu/go/support

Alexis' contact information:

Alexis Joseph

Medical Dietetics Gradate Student

440-785-2640

joseph.264@osu.edu

Enclosure (consent form) 
Appendix B: Consent Form 


\title{
The Ohio State University Consent to Participate in Research
}

\author{
Study Title: \\ Health Perceptions of Cancer Survivors Harvesting at the \\ Garden of Hope \\ Researcher: $\quad$ Spees, C.K.
}

This is a consent form for research participation. It contains important information about the Garden of Hope Study and what to expect if you decide to participate.

\section{Your participation is completely voluntary.}

Please consider the information carefully. Feel free to ask questions before making your decision whether or not to participate. If you decide to participate, you will be asked to sign this form at the Focus Group session and will receive a copy of the form.

\section{Purpose:}

The purpose of the focus groups is to better understand the barriers, benefits and overall health perceptions you experienced after harvesting at the Garden of Hope. We are completing three focus groups for $\mathrm{GOH}$ participants.

\section{Procedures/Tasks:}

If you agree to participate, you will engage in a discussion with approximately 5-10 other $\mathrm{GOH}$ participants. The questions are related to your perceptions of the Garden of Hope environment in terms of your health, as well as the barriers, challenges, and perceived benefits associated with harvesting. We also ask you to complete a short supplemental survey that asks you to share basic demographic information and answer questions about your history of cancer.

\section{Duration:}

The focus group will last approximately two hours, which includes signing the consent form, a briefing of the project, completion of a supplemental self-administered survey, and the focus group discussion.

You may leave the study at any time. If you decide to stop participating in the study, there will be no penalty to you, and you will not lose any benefits to which you are otherwise entitled. Your decision will not affect your future relationship with The Ohio State University, JCFL or GOH.

\section{Risks and Benefits:}


This study poses minimal risks for you as a participant, risks that are no more than those faced in everyday life. Note that you can skip any questions in the self-administered supplemental survey or not respond to questions in the focus group if you feel uncomfortable. We expect that the benefits outweigh the risks. This is an opportunity for you to have a voice and engage in conversations around harvesting with fellow cancer survivors that can improve the experience in the future.

\section{Confidentiality:}

Efforts will be made to keep your study-related information completely confidential. The survey and focus group interview is for research purposes only, and no individual responses will be identified. Your comments will be kept strictly confidential.

However, there may be circumstances where this information must be released. For example, personal information regarding your participation in this study may be disclosed if required by state law. Also, your records may be reviewed by the following groups (as applicable to the research):

- Office for Human Research Protections or other federal, state, or international regulatory agencies;

- The Ohio State University Institutional Review Board or Office of Responsible Research Practices;

- The Food Innovation Center supporting the study.

\section{Audio Recordings:}

The focus groups will be recorded and transcribed by trained study personnel. You will not be asked to use your last name and can use a fake first name if you want. Since audio recordings are considered potentially identifiable, once the recordings are transcribed, the recordings will be permanently destroyed.

\section{Incentives:}

A $\$ 10$ gift card will be given for participation in the study.

\section{Participant Rights:}

You may refuse to participate in this study without penalty or loss of benefits to which you are otherwise entitled. If you are a student or employee at Ohio State, your decision will not affect your grades or employment status.

If you choose to participate in the study, you may discontinue participation at any time without penalty or loss of benefits. By signing this form, you do not give up any personal legal rights you may have as a participant in this study. 


\section{Contacts and Questions:}

For questions, concerns, or complaints about the study, or if you feel you have been harmed as a result of study participation, you may contact the study investigator Colleen Spees at 614-688-4651 or Colleen.Spees@osumc.edu.

For questions about your rights as a participant in this study or to discuss other studyrelated concerns or complaints with someone who is not part of the research team, you may contact Ms. Sandra Meadows in the Office of Responsible Research Practices at 1800-678-6251.

\section{Signing the Consent Form:}

I have read (or someone has read to me) this form and I am aware that I am being asked to participate in a research study. I have had the opportunity to ask questions and have had them answered to my satisfaction. I voluntarily agree to participate in this study.

I am not giving up any legal rights by signing this form. I will be given a copy of this form.

$$
\text { Printed name of subject }
$$

Printed name of person authorized to consent for subject (when applicable)

\section{Signature of subject}

Date and time (when applicable)

Date and time

\section{Investigator/Research Staff}

I have explained the research to the participant or his/her representative before requesting the signature(s) above. There are no blanks in this document. A copy of this form has been given to the participant or his/her representative. 
Appendix C: Subject Characteristics Survey 
Health Perceptions of Cancer Survivors Harvesting at the Garden of Hope

For Researcher Use Only:

Location ID \#

Date

Moderator ID \#

Co-Moderator ID $\#$

\section{Demographic Information:}

1. Please write your age:

2. Please place an " $X$ " on the line(s) that you feel most closely describe(s) your race and ethnicity. You may check all that apply.

Latino or Hispanic
Black or African American
Asian or Pacific Islander

I do not know.
White or Caucasian Native American or American Indian Other: Please list:

I do not want to answer.

3. Please place an "X" on the line that you feel most closely describes your gender. Female ___ Male ___ Transgender or Other I do not want to answer.

4. Please place an " $X$ " on the line that indicates your current relationship status.

Married Living with partner Widowed Divorced Separated - Widowed Single, never married or in domestic partnership I do not want to answer.

5. Do you currently smoke?

6. At what age were you told that you had cancer?

7. How many types of cancers have you had? 
8. What type of cancer was it?

9. Are you currently in treatment? If not, how long have you been done with treatment?

10. If so, for how long and what type? If not, how long have you been out of treatment?

11. Have you been diagnosed with any other diseases or conditions?

Thank you so much for your time and participation in the survey and the focus groups! 
Appendix D: Food Security Questionnaire 


\section{Six Item Food Security Module}

HH3. Indicate whether the statement was often true, sometimes true, or never true for (you/your household) in the last 12 months - that is, since last November.

The food that (I/we) bought just didn't last, and (I/we) didn't have money to get more." Was that often, sometimes, or never true for (you/your household) in the last 12 months?
[] Often true
[] Sometimes true
[ ] Never true
[] DK or Refused

HH4. “(I/we) couldn't afford to eat balanced meals." Was that often, sometimes, or never true for (you/your household) in the last 12 months?
[] Often true
[] Sometimes true
[ ] Never true
[ ] DK or Refused

AD1. In the last 12 months, since last (name of current month), did (you/you or other adults in your household) ever cut the size of your meals or skip meals because there wasn't enough money for food?
[] Yes
[] No (Skip AD1a)
[] DK (Skip AD1a)

AD1a. [IF YES ABOVE, ASK] How often did this happen—almost every month, some months but not every month, or in only 1 or 2 months?
[] Almost every month
[] Some months but not every month
[ ] Only 1 or 2 months
[] DK

AD2. In the last 12 months, did you ever eat less than you felt you should because there wasn't enough money for food?
[] Yes
[] No
[] $\mathrm{DK}$ 
AD3. In the last 12 months, were you every hungry but didn't eat because there wasn't enough money for food?
[] Yes
[] No
[] DK 